DOI: http://dx.doi.org/10.22201/iie.18703062e.2017.1.2599

\title{
Jorge Alberto Manrique: El transgresor (1936-2016)
}

\author{
Jorge Alberto Manrique: The Transgressor (1936-2016)
}

Texto recibido el 27 de febrero de 20I7; aceptado el 7 de marzo de 20I7. http://dx.doi.org/IO.2220I/ IIE.I8703062e.20I7.I.2599

Miguel Ángel Rosas Facultad de Filosofía y Letras, UNAM. miguelangelrosas@gmail.com

Líneas de investigación Construcción y destrucción de las utopías arquitectónicas del siglo xx; el estudio de los imaginarios urbanos en las Exposiciones Universales de posguerra; recientemente se ha enfocado a estudiar la iconografía política, así como la traza urbana de la Ciudad de México en el siglo xix. El tema de su investigación doctoral se denomina: "México, la construcción de una ciudad sin Dios. La traza del liberalismo: 1854-I873”.

Lines of research Construction and destruction of the architectural utopias of the twentieth century; study of the urban imaginaries at the Universal Expositions of the postwar period; more recently concentrating on political iconography and the urban planning of Mexico City in the nineteenth century. The subject of my doctoral research is "México: the Construction of a City without God. The Layout of Liberalism: 1854-1873."

Publicaciones relevantes

“¿Es esto el mañana?, prefiguraciones de la ciudad rumbo al año 200o”, en El Futuro. Memorias del XXXI Coloquio Internacional de Historia del Arte (México: Universidad Nacional Autónoma de México-Instituto de Investigaciones Estéticas, 2010), 399-409; "La apropiación arquitectónica de 'El Ángelus' de Millet”, en Apropiarse del arte: impulsos y pasiones. Memorias del XXXII Coloquio Internacional de Historia del Arte (México: Universidad Nacional Autónoma de México-Instituto de Investigaciones Estéticas, 20I2), 243-258; "México D.F., la experiencia del hombre metropolitano ante el escenario de la ciudad del espectáculo", en La metrópoli como espectáculo: la Ciudad de México escenario de las artes. Memorias del XXXIV Coloquio Internacional de Historia del Arte (México: Universidad Nacional Autónoma de México-Investigaciones Estéticas, 2010), I29-I44; "La gráfica como denuncia, imágenes de sedición y rebeldía", en Denuncia gráfica: Realidades contrastantes en el México de principios del siglo XX (México: Universidad Nacional Autónoma de MéxicoCentro Cultural Universitario Tlatelolco-Museo Colección Blaisten, 20II). En coautoría con Jorge Alberto Manrique, "La pilastra estípite y sus secuelas", en Armando Ruiz, Los retablos de la Ciudad de México. Siglos XVI al XX, una guía (México: Asociación del Patrimonio Artístico Mexicano-Conaculta, 2005), 175-272. 
Resumen La trayectoria de Jorge Alberto Manrique en el mundo de la historia del arte latinoamericano traza paralelos entre su pensamiento historicista y el análisis del ambiente artístico. El interés de este tributo es abordar la vida de un hombre que buscó responder a la pregunta: ¡cómo se forma un historiador e historiador del arte? Este texto, estructurado de forma cronológica, nos familiariza primero con el Manrique previo a los encuentros con pensadores como Edmundo O'Gorman, Francisco de la Maza y Justino Fernández. ¿¿Cuáles fueron sus referencias iniciales, quiénes fueron sus maestros y cómo definió su posición a partir del historicismo son algunas de las preguntas que encuentran respuesta. La oposición dialéctica entre la historia y la historia del arte, apertura y tradición, manierismo y barroco, así como la postura de Manrique frente a lo mexicano, forjada desde el interior de una generación en tránsito, son resultado de una crisis en la que el triunfo de uno es permeado por el otro, similar a "un objeto herido en el que han quedado huellas". Ese rigor hegeliano —el giro dialéctico filosófico- es el que fundamentó su vida profesional. Así, esta semblanza, además de dejar prueba de las líneas de investigación de Manrique, es una forma de rendir homenaje a uno de los historiadores y críticos de arte más importantes, quien, entre otros aportes, impulsó al Instituto de Investigaciones Estéticas (UNAM) a abrirse al ámbito internacional.

Palabras clave historicismo; manierismo; barroco; Museo Nacional de Arte, México; Museo de Arte Moderno, México; unam.

Abstract Jorge Alberto Manrique's passage through the world of Latin American Art History draws parallels between his Historicist thought and the analysis of artistic environment. The interest of this tribute is to approach the life of a man, who sought to answer the question: How is it that an historian and an art historian are formed? Structured in a chronological manner this text familiarizes us first with Manrique before his encounters with thinkers such as Edmundo O'Gorman, Francisco de la Maza and Justino Fernández. What were his early references, who his first teachers, and, coming from historicism, how did he define his position are some of the questions answered. The dialectic opposition between History and Art History, aperture and tradition, Mannerism and Baroque, as well as Manrique's view of that which is Mexican, forged within a generation in transit, are the result of a crisis in which the triumph of one is permeated by the other, similar to "a wounded object on which traces have been left." This Hegelian rigor-the dialectic philosophical turn-fundamented his professional life. Thus this rendering, which tells of Manrique's lines of research, seeks to pay homage to one of Mexico's most important historians and art critics, whom alongside other activities, propelled the aperture of the Instituto de Investigaciones Estéticas (UNAM) to an international context.

Keywords Historicism; Mannerism; Baroque; Museo Nacional de Arte, México; Museo de Arte Moderno, México; unam. 
DOI: http://dx.doi.org/10.22201/iie.18703062e.2017.1.2599

\author{
MIGUEL ÁNGEL ROSAS \\ UNIVERSIDAD NACIONAL AUTÓNOMA DE MÉXICO \\ FACULTAD DE FILOSOFÍA Y LETRAS \\ MÉXICO
}

\title{
Jorge Alberto Manrique: el transgresor \\ (1936-2016)
}

Al león desdentado en su partida ${ }^{\mathrm{I}}$

$\mathrm{L}$

a muerte del maestro Jorge Alberto Manrique representa el fin de una época. Es el desvanecimiento de una generación de la cual sólo quedan huellas. Hace más de 20 años lo conocí cuando era un joven estudiante de la Facultad de Arquitectura en la ciudad de Puebla. El geometrismo mexicano fue mi primer acercamiento a él. ${ }^{2}$ Siempre tuve curiosidad por conocerlo. Nunca imaginé que con el paso de los años sería mi maestro, mi jefe y mi amigo. ${ }^{3}$

I. En el proceso de redacción de este texto murió Teresa del Conde; con especial carińo dedico este ensayo a mi querida maestra a quien le agradezco su apoyo desde esta distancia. Descanse en paz.

2. Jorge Alberto Manrique, Ida Rodríguez Prampolini, Juan Acha, Xavier Moyssén y Teresa del Conde, El geometrismo mexicano (México: Universidad Nacional Autónoma de México-Instituto de Investigaciones Estéticas, 1997).

3. Con mi respeto a la familia de Jorge Alberto Manrique: Mónica Mansour, Lorenza, Martín, Julián, Manrique, y sus nietos Sabina, Bruno y Adela. Agradezco el apoyo de mis maestros: Enrique X. de Anda Alanís, Hugo Arciniega, Eduardo Báez, Julieta Ortiz Gaytán y Óscar Flores. A los artistas: Raúl Herrera, Roy Sobrino, Eloy Tarcisio, Gabriel Macotela, Yani Pecanins, Vicente Rojo Cama y Ernesto Molina. A Paula Carrasco y Mariana Elizondo. A los fotógrafos: Rogelio Cuéllar y Héctor García. A mis amigas: Ángela Ramos, Andrea Montiel, Sandra Sofía Peña y Berenice Quirarte. A María del Carmen Sifuentes del Archivo Histórico del Instituto de Investigaciones 
En reiteradas ocasiones el maestro Manrique me decía: "Como no puedo escribir mis memorias te las comparto a ti”..., y así fue a lo largo de in años en los que tuve la fortuna de estar cerca de él. Me contó su vida como si fuera un rompecabezas el cual quiero unir y, en parte, ésta es la biografía que él me compartió.

Jorge Alberto Manrique Castañeda (1936-2016) fue uno de los principales gestores, historiadores y críticos de arte del siglo xx en México. Sus padres, la señora Teodosia Castañeda y del Pozo y don Luis Esteban Manrique Guillén - ambos profesores de profesión - fueron quienes le transmitieron su pasión por la docencia. 4 "Mi padre era maestro de la escuela primaria, le interesaba la geografía y la música." "Mi educación artística empezó desde mi familia: íbamos a ver muchas exposiciones. Recuerdo aún la primera que vi, fue una de José Clemente Orozco, para mí fue muy importante." ${ }^{6}$

Su abuelo Marcelino Castañeda Núńez de Cáceres (I80o-I887) fue una de las figuras de mayor relieve en el partido conservador. Fue gobernador de Durango (I837-I839 y I847-I848), ministro de Justicia en el gabinete del presi-

Estéticas [IIE]. A Rocío Gamińo, Ricardo Alvarado, Esther Tovar, Cecilia Gutiérrez Arriola, Adriana Roldán y Sandra Arzate de la Fototeca del iıE. A Alberto Sánchez y Laura Cervantes de la Biblioteca del IIE. A María Estela Duarte y Víctor T. Rodríguez Rangel del Museo Nacional de Arte; a Martha Nualart y María de los Ángeles Tepale Flores del Museo de Arte Moderno (мAM); a Jennifer Rosado Solís por su tesis: "Munal 200o"; y, especialmente a Linda Báez y Emilie Carreón.

4. Don Luis Esteban Manrique Guillén fue director por 50 años de la escuela primaria El Pensador Mexicano. El inmueble está ubicado en la calle Jaime Torres Bodet núm. 132 en la colonia Santa María la Ribera. "Mi padre [...] en la penuria que vivíamos siempre se ocupó de que en cualquier vacación saliéramos, así fuera a Toluca en tren de segunda [...] era un hombre sensible. Nos hacía ver, a mis hermanos y a mí, detalles, cosas, sorpresas. Lo hacía también en la ciudad de México, cuando viajábamos en tranvía. El tranvía [...] era un vehículo ideal para conocer la ciudad y su vida y su pasado." Véase Jorge Alberto Manrique, "Manuel Toussaint: encuentros y quehaceres", en Obras maestras del arte colonial. Exposición homenaje a Manuel Toussaint (I890-199o), ed. Elisa García Barragán (México: Universidad Nacional Autónoma de México-Instituto de Investigaciones Estéticas/Museo Nacional de Arte/CNc/Instituto Nacional de Bellas Artes, I990), II-I5.

5. "Recuerdo que cuando yo era muchacho asistía a Bellas Artes a los conciertos de la Sinfónica y los ballets, con la música de [Blas] Galindo que después escuché en muchos foros." Véase Jorge Alberto Manrique, "Respuesta", en Carlos-Blas Galindo. Discurso de ingreso a la Academia de Artes. Mi itinerario crítico (México: Academia de Artes, 2007), 19. Los primeros artículos de Manrique serán de música, como refirió Teresa del Conde en su participación en el Homenaje de Jorge Alberto Manrique por sus 80 ańos.

6. Jorge Alberto Manrique, "Una visión contemporánea de la historia del arte”, en Concepción Salcedo Meza, Expresiones... por escrito (México: Universidad Nacional Autónoma de MéxicoCoordinación de Difusión Cultural-Dirección General de Televisión Universitaria, 2003), I53. 
dente José Joaquín de Herrera (1848-I849), presidente de la Suprema Corte de Justicia, y diputado al Congreso Constituyente (I856-1857). 7 Se casó con Concepción Romero, su abuela.

Las tías de Jorge Alberto fueron Teodosia y Estefanía Castañeda Núñez de Cáceres, ambas pedagogas. ${ }^{8}$ Estefanía fue fundadora de la educación preescolar en nuestro país. Influida por las novedosas teorías educativas de Federico Fröbel y Johann Heinrich Pestalozzi fundó el primer Jardín de niños.

Fröbel introdujo el concepto de "trabajo libre" en la pedagogía: las actividades eran cantar, actuar, trabajar y hacer tareas, es decir, fundamentó la educación de los niños en la diversión. ${ }^{9}$ Esas ideas sobre el desarrollo infantil y la educación las introdujo en México Estefanía Castañeda, tía de Jorge Alberto Manrique. El maestro creció, por tanto, en un ambiente donde se le dio una importancia capital a la libertad de expresión ${ }^{\mathrm{IO}}$ y al ser hijo de pedagogos conoció de primera mano la importancia de la educación primaria. ${ }^{\mathrm{II}}$

\section{Primera educación}

Manrique estudió en la escuela primaria pública de Azcapotzalco. "Tuve como texto La patria mexicana de Gregorio Torres Quintero, de amenísima lectura, con una idea muy clara (lo veo ahora) de lo que debía ser la enseñanza de la historia." ${ }^{2}$

La educación primaria junto con la educación casera le proporcionarían a mi joven maestro el primer atisbo a la historia.

Al no haber secundaria en Azcapotzalco, Jorge Alberto se traslada a la Secundaria 4 en San Cosme.

7. Humberto Musacchio, Diccionario enciclopédico de México (México: Raya en el Agua, 2006), 198.

8. Teodosia fue una eminente educadora que fundó en Victoria el primer Colegio Nocturno para Señoritas y la Primera Escuela Normal para Profesoras en 1900. Sus padres fueron el doctor Zeferino Castañeda y Manuela Núñez de Cáceres. Murió el 2 de agosto de 1959.

9. Para profundizar en el tema recomiendo consultar Friedrich Froebel: A Select from his Writings (Cambridge University Press, 1967).

Io. Jorge Alberto Manrique sería un gran defensor de la libertad en sus diferentes facetas: la salvaguarda de monumentos y la libertad de creación son algunas de éstas.

II. El libro de texto gratuito de historia y civismo del sexto ańo de primaria parte de ese interés. Más adelante me referiré a él.

I2. Enrique Florescano y Ricardo Pérez Montfort, comp., Historiadores de México en el siglo XX (México: Consejo Nacional para la Cultura y las Artes-Fondo de Cultura Económica, 1995), 427-434. 
La Secundaria 4 estaba y está en el viejo edificio que fue escuela de jesuitas, lo que ya era una incitación. La educación fue muy buena e inducía a un espíritu débil como el mío a interesarse en ciertas cosas. [...] Los maestros eran famosos más allá de lo imaginable: Carlos Pellicer, Rita López de Llergo, Maximino Martínez. [...] Un maestro Macías, nos abrió los ojos a muchas cosas, y Juan Antonio Ortega y Medina, nos proponía formas inusitadas y fascinantes de comprensión de los hechos históricos $[\ldots]^{13}$ los textos de historia universal eran el Ducudrey y el Malet e Isaac.

Los chamacos de la secundaria nos escapábamos con el pretexto de ir a comprar cola o clavos y nos metíamos a Mascarones — a la Facultad de Filosofía y Letras-a las clases de Justino Fernández, Samuel Ramos, Wenceslao Roces, Eduardo Nicol o José Gaos (no supe entonces de Edmundo O'Gorman) y nos sentábamos muy serios, sin entender casi nada. [...] Para un escuincle de secundaria Mascarones significó [...] lo más extraordinario de México. ${ }^{14}$

La familia Manrique Castańeda vivía en una vieja casona de Azcapotzalco en la calle Lerdo de Tejada muy cerca del convento dominico. El contacto cotidiano con la capilla de San Francisco, la del Rosario, y el cuadro de Miguel Cabrera de su madre serían su primera entrada al mundo del arte. ${ }^{\mathrm{Is}}$

Manrique estudió en la Escuela Nacional Preparatoria ubicada en el maravilloso palacio-colegio de San Ildefonso, del siglo XviII: "Se necesitaría haber sido de piedra para no conmoverse ante El Generalito, con la sillería de San Agustín, obra nunca suficientemente bien ponderada de Tomás Ocampo, donde nos bajaron los calzones para hacernos el examen médico." ${ }^{6}$

En aquella época, en la preparatoria, había contraposición entre una enseñanza tradicional y conservadora representada por Salvador Azuela y Pérez Verdía (hijo) y una historia antigua de México de tintes modernos.

Nos resultó muy propicio que a una cuadra de distancia estuviera El Colegio

Nacional; con el menor pretexto, en horas libres o saltándonos clases, nos íbamos a

13. La importancia de Juan A. Ortega y Medina será crucial en su formación; Manrique lo incluye al igual que Edmundo O'Gorman y Francisco de la Maza en sus agradecimientos de su tesis y primer libro Los dominicos y Azcapotzalco. Estudio sobre el convento de predicadores en la antigua villa (Jalapa: Universidad Veracruzana, 1963).

I4. Manrique, "Manuel Toussaint", I2.

I5. Agradezco a Hugo Antonio Arciniega la plática sostenida el día miércoles I de febrero de 2017.

I6. Manrique, "Manuel Toussaint", I2. Para Jorge Alberto Manrique, San Ildefonso era también los murales de Orozco. 


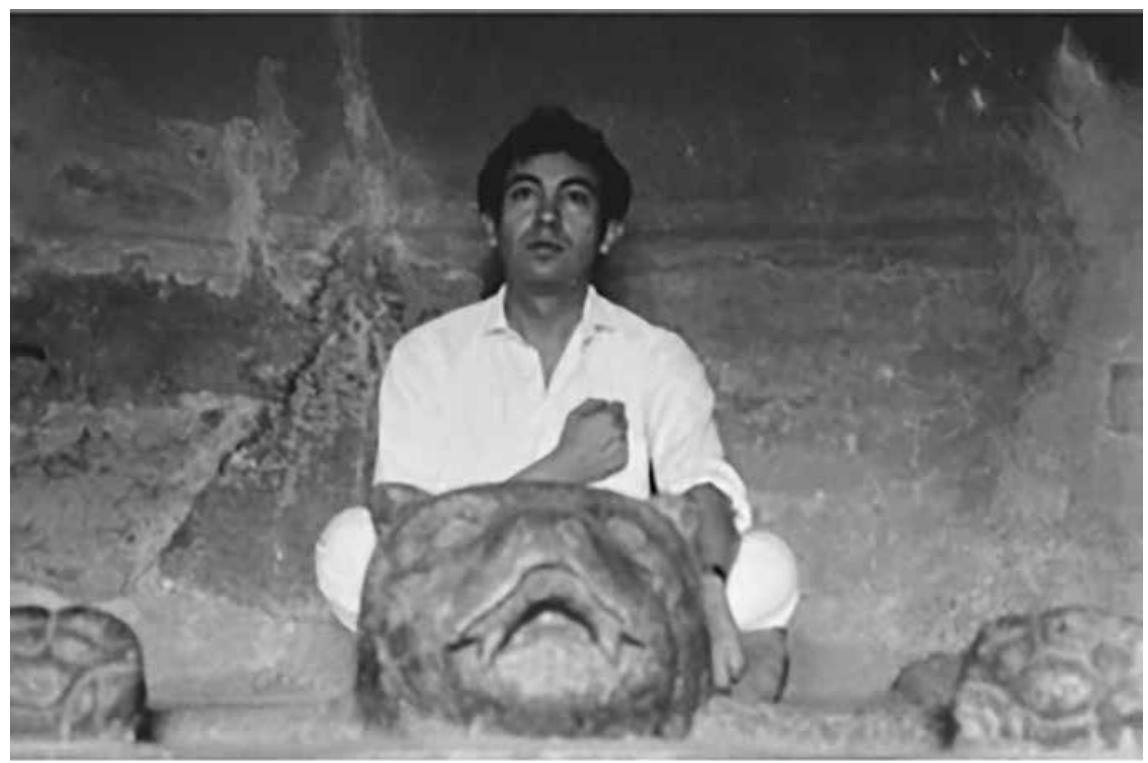

I. Jorge Alberto Manrique en Malinalco, ca. 1960. Archivo: Jorge Alberto Manrique.

oír a aquellos señorones: José Vasconcelos, Alfonso Reyes y, para el efecto, Alfonso Caso, Manuel Toussaint, e incluso Diego Rivera, amén de otros. [...] El ambiente intelectual era extraordinariamente favorable para que un joven como yo sucumbiera ante la historia. [...]

Muy cerca de la preparatoria, en la calle de Cuba, estaba el cine Río que exhibía desde las once de la mañana películas que entonces parecían pornográficas y eran nuestras escapadas en las horas libres, veíamos Un solo verano de felicidad ${ }^{17}$ o Arroz $^{2}$ amargo. ${ }^{18}$

La atracción de la Escuela Nacional Preparatoria, El Colegio Nacional, y en general el Barrio Universitario era tan fuerte que los estudiantes que pasaban a Derecho o a Filosofía y Letras no dejarían de frecuentarla. "Yo vivía en Azcapotzalco pero me la pasaba allí en el centro, en ese ambiente extraordinario, con mucha actividad cultural e intelectual."

17. Dirigida por Arne Mattson en I951.

I8. Dirigida por Giuseppe de Santis en 1949 y protagonizada por Vittorio Gassman y Silvana Mangano. Manrique, "Manuel Toussaint", I2.

I9. Entrevista personal a Jorge Alberto Manrique. A partir de aquí: Entrevista a J.A.M. 
DOI: http://dx.doi.org/10.22201/iie.18703062e.2017.1.2599

Paralelo a sus estudios preparatorianos Manrique asistía al Instituto Francés de América Latina (IFAL). Ahí se llegó a conformar un grupo de teatro con: María Cristina, Cristina — chica—, Mercedes y Asunción Stoupignan, Gastón Melo, Héctor Ortega, Jorge Alberto Manrique, y otros más. ${ }^{20}$ En 1956 montaron: El enfermo imaginario y Las preciosas ridiculas, ambas comedias de Molière, en francés. ${ }^{2 \mathrm{I}}$

El inicio de las fiestas y tertulias literarias en la vida de Jorge Alberto Manrique fue en la casa de las Stoupignan en el famoso Tabasco $313 .{ }^{22}$

\section{Facultad de Filosofía y Letras, UNAM}

Manrique estudió la licenciatura en Historia en la Facultad de Filosofía y Letras de la UNAM entre 1955 y 1958. "Empecé a estudiar historia después de haber transitado por un jugosísimo año de jurisprudencia y otro pedazo de geografía en el Instituto que dirigía Rita López de Llergo. Ahí trabajaba dibujando mapas con una media plaza que me gané. Éstas fueron creadas para que los estudiantes pudiéramos ayudarnos." ${ }^{23}$

20. Fernando Macotela, conferencia en homenaje a Jorge Alberto Manrique por sus 80 años en el Museo de Arte Moderno.

2I. El maestro Manrique conservó en su archivo dos fotografías de dichas representaciones.

22. Héctor Ortega, conferencia en homenaje a Jorge Alberto Manrique por sus 80 años. Las fiestas y tertulias literarias fueron muy importantes para esa generación. En entrevista con Rogelio Cuéllar refiere: "La casa de Juan García Ponce era un gran centro de reunión, cantaba Teresa del Conde, Ismael Guardado tocaba la guitarra, la convivencia era muy interesante, se reunían Huberto Batis, Héctor García, Abelardo Villegas, Margarita Peña, José de la Colina, Hernán Lara. [...] Las célebres cenas del día is de septiembre en la casa de Jorge Alberto Manrique. Él se ponía sombrero de copa y corbata de bandera. Una vez nos hicieron bailar en mallones y con globos cantando 'Pompas ricas', era la fiesta, era la irreverencia. Se organizaban cenas de colores..., eran como una familia. [...] La galería Pecanins era otro centro, las famosas fiestas de los pasteles en la casa de María Teresa y Ana María Pecanins en el famoso edificio Condesa”. En entrevista con Gabriel Macotela me compartió el recuerdo de una fiesta en la casa de las Pecanins. "Estaban: Octavio Paz, Carlos Fuentes, Carlos Monsiváis, Rufino Tamayo, Olga, José Luis Cuevas con Bertha, Vicente Rojo, Manuel Felguérez, Mario Vargas Llosa, Fernando de Szyszlo, Gunther Gerzso, Mathias Goeritz, Francisco Toledo..., ésas eran las fiestas. Estaba más unido el gremio artístico, Manrique era muy divertido, aprendías mucho de él, de su sentido del humor, siempre fue un espíritu joven hasta que murió."

23. Entrevista a J.A.M. 
En la licenciatura fui discípulo de los fundadores del Instituto de Historia, don Rafael García Granados y don Pablo Martínez del Río, quienes daban clase todavía en la Facultad; ya eran viejos, por desgracia, y ya no estaban en su mejor momento. Para quienes llegábamos con una idea previa, como yo (en mi caso la historia del arte), estaba Justino Fernández y Francisco de la Maza —a quien Toussaint había heredado la clase hacía no mucho-, ambos excelentes y de quienes se podía aprender muchísimo; muerto Salvador Toscano, ocupaba su clase José Servín y estaba [...] el gran representante del marxismo y aureolado de sabiduría Wenceslao Roces, quizá un tanto desperdiciado. Las grandes revelaciones, eran sin duda, Juan A. Ortega y Medina $^{24}$ y, sobre todo, Edmundo O'Gorman. ${ }^{25}$

En aquella época en la Facultad estaba la vieja planta de profesores tradicionales (positivistas) y la “nueva ola”, la del historicismo, con O'Gorman a la cabeza.

A los tradicionales les parecía un despropósito; decían que eso era filosofía y no historia. Era una guerra intelectual, pero también era una guerra de posiciones de grupo. La pugna era muy fuerte entre esas dos corrientes y los estudiantes tomábamos partido afiliándonos a una o a otra. [...] Cuando yo estudié, prevalecía un acuerdo muy viejo de colaboración entre la Facultad de Filosofía y la Escuela de Antropología, mismo que se remontaba a los orígenes de estas instituciones; [...] Yo tomé clases en la Escuela de Antropología, en el Palacio de Moneda. La planta de los iniciadores de la escuela antropológica mexicana se había enriquecido con algunos grandes exiliados españoles, como Pedro Bosch y Juan Comas, u otros transterrados, como Mauricio Swadesh o Paul Kirchhoff. Ahí tuve como maestro a Pedro Armillas. ${ }^{26}$

Paralelo a ello, Manrique frecuentaba los talleres de pintura de la Academia de San Carlos: "A mí siempre me interesó ver la producción de jóvenes pintores." ${ }^{7}$

En la Facultad, Manrique descubrió lo siguiente: "Siempre he creído que tanto en la historia como en la historia del arte debe imponerse el rigor: en la

24. Juan A. Ortega y Medina fue combatiente del lado de la República en la Guerra Civil Española y llegó a México en tiempo de la posguerra. En clase se discutía sobre lo justo y lo injusto de la conquista española, sobre la "didáctica de la historia" o sobre los ejemplos de confección historiográfica. Agradezco a Eduardo Báez la charla sostenida el día I de febrero de 2017.

25. Florescano, "Historiadores de México", 429.

26. En aquella época Jorge Alberto Manrique adquiriría junto con su hermano Leonardo el libro Sellos prehispánicos de Jorge Enciso, ejemplar que ocupó un lugar especial en su biblioteca personal.

27. Entrevista a J.A.M. 
recolección de datos y en su análisis, pero sobre todo en los planteamientos conceptuales. Es la única manera de reexaminar las verdades existentes y proponer las nuestras, que deben ser el testimonio de nuestra época." ${ }^{28}$

Con esos postulados se enfrentó a su primer tema de investigación, la tesis: "Los dominicos y Azcapotzalco. Estudio sobre el convento de predicadores en la antigua villa”. Ahí hace conciencia del hecho histórico y artístico del edificio, pese a ello descubre algo más, las lecturas sobre el barroco de Werner Weisbach como estilo de la Contrarreforma. ${ }^{29}$ En esta época Manrique aún no era consciente del manierismo, pero desde ahí empezó a recorrer el camino para definir su teoría. Estas inquietudes lo llevarán a establecer contacto con Victor-Lucien Tapié y Giulio Carlo Argan. Al terminar los estudios de licenciatura Jorge Alberto Manrique era la joven promesa.

\section{Jalapa}

A poco de haber egresado a Jorge Alberto lo contrató Fernando Salmerón como profesor e investigador por la Universidad Veracruzana para la Facultad de Filosofía y Letras de Jalapa. ${ }^{30}$ Pasaría cuatro años en dicho lugar (1958-1962). Sus primeras actividades se llevaron a cabo en el Seminario de Historia Contemporánea donde se abordó la Historia de la Revolución en Veracruz. Su existen-

28. Florescano, "Historiadores de México", 430.

29. Me refiero al libro: Werner Weisbach, El barroco. Arte de la contrarreforma (Madrid: Espasa Calpe, 1948). Material citado en su tesis de licenciatura.

30. "Entonces se habían hecho ya dos intentos por formar facultades de letras en las universidades de Guanajuato y de San Luis Potosí y allá habían ido algunos profesores jóvenes, pero ya con algún merecido prestigio (Guerra, Rius, Villoro...)”. Los cambios entonces tan frecuentes en las universidades estatales habían hecho fracasar esos intentos al poco tiempo. Cuando a Gonzalo Aguirre Beltrán lo nombraron rector de la Universidad Veracruzana, encargó al joven Salmerón la fundación de la facultad. [...] el ensayo de Jalapa prosperó gracias al empeño de Fernando Salmerón. [...] Primero como director de la facultad y luego secretario general, después ya como rector concibió una verdadera universidad, en la docencia y la investigación, en las múltiples actividades, desde la editorial y la revista La Palabra y el Hombre, con Sergio Galindo a la cabeza, el Instituto y el Museo de Antropología, teatro, sinfónica, galería, Escuela de Bellas Artes y muchos etcéteras”. Véase Jorge Alberto Manrique, “Fernando Salmerón”, México, La Jornada, II de junio de 1997 , año XIII, núm. 4585, 29. 
2. Jorge Alberto Manrique.

Foto: Pedro Cuevas. Archivo

Fotográfico Manuel Toussaint, IIE-UNAM.

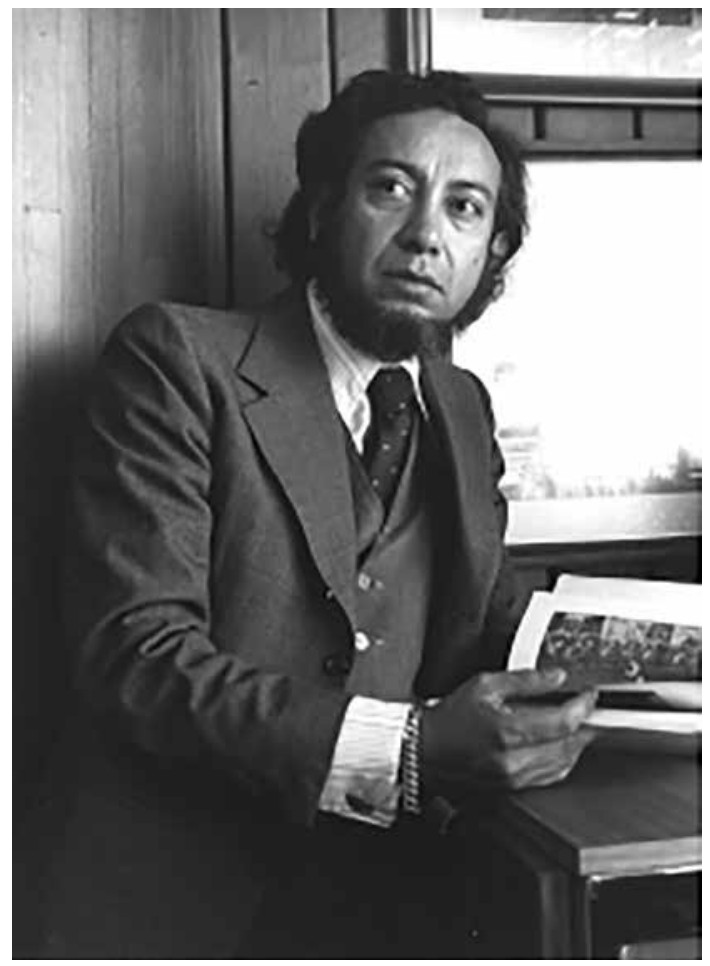

cia fue posible gracias a un acuerdo de ayuda entre la propia Universidad y la Fundación Rockefeller. ${ }^{31}$

En 196I lo nombraron director de la Escuela de Historia a los 25 años de edad. Manrique vivió en aquella época en el callejón del Diamante número 7. En Jalapa creó una vida veracruzana muy activa y rica al lado de: Kiyoshi Takahashi, Marie-Louise Ferrari, Emilio Carballido, Helio Flores, Leonor Anaya, entre otros. ${ }^{32}$

3I. Dicho seminario funcionó con tres investigadores como profesores de la Facultad de Filosofía y Letras: Xavier Talavera Alfaro, David Fernández Lavoignet y el propio Jorge Alberto Manrique, así como ocho ayudantes de investigación que fueron alumnos de la Facultad. Véase La Palabra y el Hombre: Revista de la Universidad Veracruzana IV, núm. I6 (Jalapa, octubrediciembre, 1960): 159-170.

32. En enero de 2006, unos meses después de haber recibido el premio Nacional de Ciencias y Artes, acompañé a Jorge Alberto Manrique a Jalapa. Recorrimos la ciudad en busca de sus lugares y me mostró los restos de la casa donde vivía, su oficina y el salón donde dio clases. Además nos dimos a la tarea de encontrar las huellas de la obra escultórica de Kiyoshi Takahashi. 
DOI: http://dx.doi.org/10.22201/iie.18703062e.2017.1.2599

288

MIGUEL ÁNGEL ROSAS

En 1959 Manrique recibió el Premio Paul Westheim a la crítica joven por su ensayo: "La madre' de Juan Soriano". A partir de ello Fernando Benítez lo invitó a colaborar en el suplemento cultural "México en la Cultura" del periódico Novedades. ${ }^{33}$

\section{Europa}

En 1962 con una beca de la Fundación Rockefeller en combinación con otra de El Colegio de México, otorgada por Daniel Cosío Villegas, Manrique realizó estudios de posgrado en las universidades de París y de Roma de 1962 a I963 y de 1964 a 1965 , respectivamente.

A los 26 años en el Centre des Recherches sur la Civilisation de l'Europe Moderne de la Universidad de la Sorbona, Manrique desarrolló con VictorLucien Tapié el proyecto de investigación: "La influencia india en el barroco mexicano".

Manrique vivió un año en La Casa de México en París, donde coincidiría con: Tomás Pérez Turrent, Paul Leduc, Francisco Toledo, Rodolfo Nieto, Raúl Herrera, Emilio Ortiz, Rodolfo Stavenhagen, Julio Labastida, Sylvia Pandolfi, Marcos Cuéllar, Ivonne Cadar, Manuel Bartlett, entre otros.

Uno de sus compañeros en esa época fue el pintor Raúl Herrera:

Fueron años muy álgidos, había en el ambiente resabios de la guerra de Argelia [...] Fue muy interesante ese París, el situacionismo estaba muy presente y traía muchas teorías.

La vida en los cafés era muy importante [...] veíamos mucho cine: Claude Chabrol, Jean-Luc Godard, Jacques Rivette, François Truffaut, cine de la nueva ola francesa [...] compartimos novias, muchas botellas y disfrutábamos el vino más barato. ${ }^{34}$

Del 8 de enero de 1963 al I5 de octubre de 1964 Jorge Alberto Manrique permanecería en la Universidad de Roma en el Instituto de Storia dell'Arte con los profesores Giulio Carlo Argán y Maurizio Bonicatti tomando los cursos de perfezionamiento en Historia del Arte Moderno.

33. Participó solamente con dos artículos: "Barclay, un nuevo pintor", Novedades, sección "México en la Cultura", 4 de septiembre de 1960 y "Kiyoshi Takahashi. Un escultor japonés", Novedades, sección "México en la Cultura", i3 de octubre de I96I.

34. Agradezco a Raúl Herrera la charla sostenida en enero de 2017. 
Yo fui a Roma buscando a Giulio Carlo Argán, después de haberlo leído. ${ }^{35}$ Desde París le escribí a Argán y contaba con su aceptación. [...] Escribía lo mismo, entonces, de la escultura manierista italiana que sobre Vedova o sobre la despuntante arte povera. [...] y también hacía crítica de arte. Casos como el de Argán no son comunes. ${ }^{36}$ En las ausencias de sus viajes lo sustituía Bonicatti, pero qué capacidad, sabiduría y personalidad. Me encontraba a veces con Argán en la parada del tram, del lado de Castro Pretorio, que me llevaba directamente a Piazza San Silvestro, de donde caminaba dos cuadras al Panteón y una más a Piazza Sant'Eustachio donde estaba mi palacio Cenci-Maccarani ${ }^{37}$ y mi guarida compartida. [...] desde mi terracita parecía casi poderse tocar la linternilla espiral de Borromini en Sant'Ivo alla Sapienza (la vieja Universidad).$^{3}$ La casa tenía unos ventanales gigantes desde donde veíamos enfrente a las estudiantes gringas desvestirse. ${ }^{39}$ En la propia vía della Valle había entonces muebleros de viejo. Ahí, con aquellos despojos [...] amueblé mi cuarto. Nunca he tenido una mesa más espléndida para trabajar, se necesitaron cuatro hombres para poder subirla al tercer piso. Y abajo estaba — y está, a Dios gracias - el café Sant'Eustachio. El mejor café de Roma, que es como decir el mejor café del mundo. ${ }^{40}$

Su estancia en Europa fue tan importante que durante toda su vida albergó dos grabados muy significativos para él, ambos ubicados en el pasillo que conducía a su habitación. Uno de 1756 , obra de Giuseppe Vasi, le recordaba su estancia en Roma y otro la de París. ${ }^{\mathrm{I}}$

35. "El sentimiento de intranquilidad que se apodera del espectador en los Uffizi, se intensifica hasta convertirse en desasosiego en el vestíbulo de la Laurenciana (proyectado en 1524). Aquí Miguel Ángel hace desaparecer, no sólo la unidad, el equilibrio y el ritmo armonioso de la arquitectura clásica, sino también la lógica tectónica dominante en ella. [...] El anticlasicismo del arte manierista significa, en el fondo, la negación de la normatividad." Véase Arnold Hauser, El manierismo: La crisis del Renacimiento y los orígenes del arte moderno (Madrid: Guamarra, 1965), 304. Ése fue el gran ejemplo del manierismo que aprendió Jorge Alberto Manrique en Roma. Agradezco a Hugo Arciniega la observación.

36. Jorge Alberto Manrique y Teresa del Conde, Cartas absurdas. Correspondencia entre Teresa del Conde y Jorge Alberto Manrique (México: Azabache, 1993), 24.

37. Obra de Giulio Romano.

38. Manrique y Del Conde, Cartas absurdas, 36-37.

39. Entrevista con Raúl Herrera.

40. Manrique, Cartas absurdas, I39.

4I. En esta época Manrique adquiere en París un grabado de Coatlicue, obra de Carl Nebel. Remembranza de su maestro Justino Fernández. 
DOI: http://dx.doi.org/10.22201/iie.18703062e.2017.1.2599

290

MIGUEL ÁNGEL ROSAS

\section{Seminario de historiografia}

A su regreso se incorporaría a El Colegio de México como profesor investigador en el Centro de Estudios Históricos, de 1964 a 1970. En la UNAm ingresó al seminario de historiografía de Edmundo O'Gorman, como parte de sus estudios de doctorado, donde estaban Josefina Zoraida Vázquez, Eduardo Blanquel — miembro por un breve periodo- Aurelio de los Reyes, Virginia Guedea y algunos miembros de El Colegio de México como Elías Trabulse y Andrés Lira. "El seminario tuvo distintas etapas: primero empezó como seminario de comentarios de textos [...] Después don Edmundo lo fue dirigiendo hacia la realización de tareas comunes: la primera fue la edición de la Apologética historia de Fray Bartolomé de las Casas. Así hicimos las Actas de cabildo y la edición que nunca se publicó de Gage, entre otros."12

\section{Libro de texto gratuito — sexto año-}

Con Eduardo Blanquel concursaría para el libro de texto gratuito de historia y civismo del sexto grado de primaria de 1967. "Nos pusimos una regla, escribiríamos solamente de lo que supiéramos". ${ }^{43}$ Manrique se encargaría del contenido, y Blanquel de la selección de imágenes.

Nos iba mucho en ello, porque significaba la oportunidad de llegar a millones de nińos y nos parecía la posibilidad de establecer el puente necesario entre la academia y la escuela primaria $[\ldots]$ nos importaba mucho ganar el concurso $[\ldots]$ terminábamos las noches sudando y enmorrińados, [...] para enfrentarnos al día siguiente ante los respetables pero poco comprensivos miembros del Consejo de Educación. ${ }^{44}$

Al ganar el concurso: "Martín Luis Guzmán, entonces presidente de la Comisión del Libro de Texto Gratuito, se tomaba el trabajo de revisar y corregir todas y cada una de las páginas escritas, y de hacer, [...] las recomendaciones

42. Entrevista a J.A.M.

43. Entrevista a J.A.M.

44. Jorge Alberto Manrique, "Eduardo Blanquel”, México, La Jornada, 2 de junio de I987, año III, núm. 973, 26. 


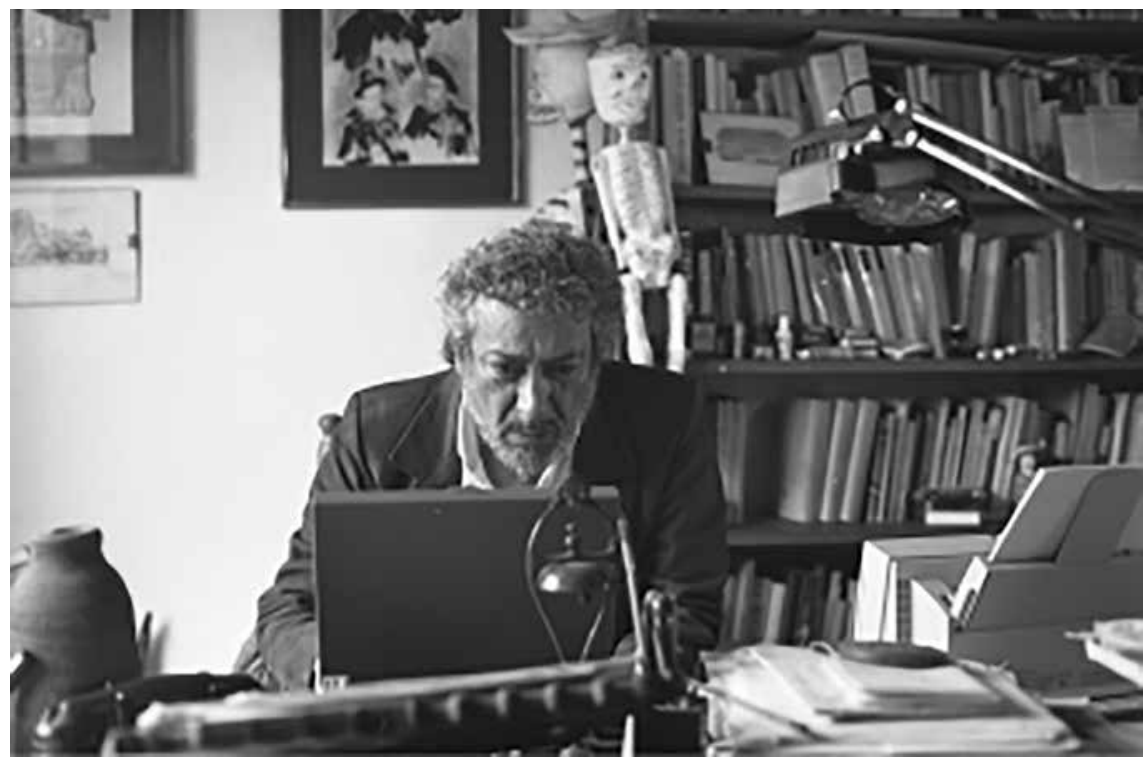

3. Jorge Alberto Manrique en su estudio. Foto: Ernesto Peñaloza. Archivo Fotográfico Manuel Toussaint, IIE-UNAM.

pertinentes. El privilegio de que don Martín comentara y corrigiera mi escritura es uno de mis mejores recuerdos."45

Con el premio del concurso compró a instancias de una amiga su primer departamento. Manrique había decidido adquirir uno en el multifamiliar Miguel Alemán de Mario Pani, pero al no haber tendederos se decidió por la colonia Del Valle.

\section{Instituto de Investigaciones Estéticas}

Posteriormente fue profesor adjunto e interino de Francisco de la Maza; impartió los cursos Reforma y Contrarreforma y Arte Colonial Mexicano desde 1966. Ingresó al Instituto de Investigaciones Estéticas de la UNAM como investigador de tiempo completo en 1968. El 27 de marzo de 1973 fue electo Miembro de Número de la Academia Mexicana de la Historia, ocupó el sitial 7 que fuera

45. Jorge Alberto Manrique, "Libros de texto gratuitos [I]", México, La Jornada, 8 de enero de I992, año VIII, núm. 2630, 34. 
de Justino Fernández. ${ }^{46}$ Su discurso de recepción: "Ambigüedad histórica del arte mexicano" (9 de octubre), se centró en la apertura del manierismo resultado de la crisis novohispana (siglos XVI-XVII) y la cerrazón del barroco dieciochesco. La respuesta fue del director de la Academia, Edmundo O'Gorman.

El 2 de diciembre de 1974 Jorge Alberto Manrique tomó protesta como director del Instituto de Investigaciones Estéticas a la edad de 38 años.

Desde mis días de estudiante ambicioné poder llegar a ser investigador de este Instituto; nunca ambicioné ser director, aunque pensé siempre que si algún día se presentara el caso tampoco lo rechazaría. Ese día ha llegado mucho más pronto de lo que habría podido imaginar [...] Confieso ingenuamente que la sorpresa se ha trocado en gusto, y que a éste se mezcla, también, no poco susto. Aceptar esa honrosa designación implica para mí el compromiso de empeñarme, en la medida de mis capacidades, primero, en ver que se mantenga la calidad de investigación que es tradicional en el Instituto, segundo, en propiciar los cambios que siento necesarios en nuestra institución. ${ }^{47}$

En su plan de trabajo denominado: "Reflexión sobre las posibilidades hacia el futuro del Instituto de Investigaciones Estéticas", se destaca lo siguiente: "Se hace casi urgente el ingreso de nuevos investigadores." En su gestión ingresaron por concurso de oposición: Teresa del Conde, Rita Eder, Fausto Ramírez y Alberto Dallal. A pesar de los méritos tan relevantes de Luis Cardoza y Aragón, la Comisión Dictaminadora no pudo elegirlo porque el Estatuto del Personal Académico impedía el ingreso a la Universidad a personas mayores de 70 años. ${ }^{48}$ Como director Manrique también propició el ingreso de los becarios: Cecilia Gutiérrez Arriola, José Guadalupe Victoria, Esther Acevedo, entre otros. Jorge Alberto Manrique además de haber hecho una gran labor, fue un director justo y equitativo con todos, académicos y administrativos.

46. Antes de él había ocupado el lugar: "ese caballero ejemplar, fundador de esta Academia y su director largos años [...] que fuera don Manuel Romero de Terreros". Véase Jorge Alberto Manrique, Una visión del arte y de la historia, t. I (México: Universidad Nacional Autónoma de México-Instituto de Investigaciones Estéticas, 200I), 85.

47. Jorge Alberto Manrique, "Palabras en la toma de posesión de Jorge Alberto Manrique como director del Instituto de Investigaciones Estéticas de la Universidad Nacional Autónoma de México", Anales del Instituto de Investigaciones Estéticas XI, núm. 44 (1975): 7-IO.

48. Archivo Histórico-Instituto de Investigaciones Estéticas-Universidad Nacional Autónoma de México [en adelante AHIIE], sección: Dirección, caja I, año I977, exp. I6I, ff. I53. 
El I de abril de 1977 ingresaron los artistas y escultores: Manuel Felguérez, Federico Silva y Julio Estrada, académicos de la Coordinación de Humanidades; dicha decisión causó polémica con el Colegio de Investigadores. ${ }^{49}$ Pese a ello la finalidad de Manrique no era abrir el Instituto a artistas sino generar nuevos campos de conocimiento hacia lo que él denominó: "la investigación teórico-práctica". ${ }^{\circ}$

"Por lo que toca al Archivo Fotográfico - que nos enorgullece- y a la Biblioteca [...], tenemos el compromiso de mantenerlos y acrecentarlos de acuerdo a planes lógicos y racionales. [...] La Biblioteca debe fortalecer su sección instrumental y formar su inexistente sección de teoría, así como enriquecer la sección de periódicos." ${ }^{\prime}$

La impresión en plata sobre gelatina fue de vital importancia en la administración de Jorge Alberto Manrique. El Archivo Fotográfico en esa época era básicamente de diapositivas y muy escaso en fotos blanco y negro, es por ello que durante su administración se adquirió el primer laboratorio fotográfico para la Fototeca del Instituto. Rafael Rivera imprimió la primera fotografía blanco y negro, misma que presentó Manrique en el Colegio de Investigadores. ${ }^{52}$

Jorge Alberto Manrique propició durante su gestión la creación de una colección de arte para la UNAM. Gustavo Curiel menciona lo siguiente: "Manrique hizo las gestiones necesarias para que el Instituto adquiriera una punta seca, impresa en el taller de Francisco Díaz de León, del Prometeo de José Clemente Orozco, pintado en 1930 en el Pomona College de Claremont, California. A él debemos también la compra de la colección fotográfica de Luis Márquez Romay," 53 y también la serie de grabados de Federico Cantú.

Pese a ello, su principal interés era hacer una colección de arte de jóvenes pintores mexicanos; generación que denominará Teresa del Conde de la rup-

49. AHIIE, sección: Dirección, caja I, año I977, exp. I6I, ff. 95.

50. AHIIE, sección: Dirección, caja I, año I977, exp. I6I, ff. 98.

5I. AHIIE, sección: Dirección, caja I, año I977, exp. I6I, ff. 99-IO0.

52. Cecilia Gutiérrez Arriola, "Entrevista a Elisa Vargaslugo", en De arquitectura, pintura y otras artes. Homenaje a Elisa Vargaslugo (México: Universidad Nacional Autónoma de México-Instituto de Investigaciones Estéticas, 2012), 523.

53. Gustavo Curiel, "Una mirada a las colecciones del Instituto de Investigaciones Estéticas de la Universidad Nacional Autónoma de México", en Catálogo de la exposición 60 años del Instituto de Investigaciones Estéticas (México: Universidad Nacional Autónoma de México-Instituto de Investigaciones Estéticas, 1996), II. 
DOI: http://dx.doi.org/10.22201/iie.18703062e.2017.1.2599

tura. "En esa época era baratísimo adquirir obra de ellos, además eran nuestros amigos [...] Los directores posteriores no le dieron continuidad." 54

Otra idea académica que impulsó fue la organización anual de coloquios internacionales de Historia del Arte.

En 1975 el Instituto de Investigaciones Estéticas conmemoraba sus 40 años de vida. El tema sería propuesto por Ida Rodríguez Prampolini: La dicotomía entre arte culto y arte popular. El evento se llevó a cabo los días in a I4 de agosto de 1975 en Zacatecas gracias al apoyo - entre otros- de Federico Sescosse. ${ }^{55}$ Paralelo a ello se inauguró la Mesa Redonda sobre el estado actual de las investigaciones del arte en México.

El coloquio, de primerísimo nivel académico, contó con la participación de George Kubler, Michel Ragon, Marta Traba, Mario Pedrosa, Enrique Marco Dorta, Donald Robertson, Adelaida de Juan, entre otros. Entre los comentaristas estaban: Edmundo O'Gorman, Mariana Frenk, Teresa del Conde, Rita Eder, Alberto Ruz L'huillier, Eduardo Matos Moctezuma, Constantino Reyes Valerio, entre otras personalidades.

Manrique presentó el texto denominado "Categorías, modos y dudas acerca del arte popular", y su comentarista fue Kazuya Sakai, pintor argentino, crítico de arte y precursor del geometrismo en México.

En los preparativos del coloquio Manrique decidió invitar a Umberto Eco y a Octavio Paz como comentarista. Jorge Alberto recibió un telegrama de Eco aceptando presentar su ponencia — desconozco al día de hoy los motivos de su cancelación. ${ }^{56}$

Paralelo a los preparativos del coloquio, en 1974, dio inicio al proyecto colectivo de la Ciudad de México ${ }^{57}$ tomando como antecedente la Guida d'Italia Roma, Touring Club italiano. Ese mismo año y en colaboración con su ex alumna Teresa del Conde, comenzarían con las memorias de Inés Amor. Fueron 52 entrevistas realizadas a partir del io de abril de 1974. Éstas verían la luz I2 años después. ${ }^{58}$ Inés Amor donó su archivo de correspondencia y fotográfi-

54. Entrevista a J.A.M.

55. Las palabras públicas que entonces se dijeron respecto a ese hecho quedaron recogidas en el volumen XIII, núm. 45, 1976 de los Anales del IIE y ahí se consignan las instituciones y personas que hicieron posible la reunión académica.

56. AHIIE, sección: Dirección, caja I, año I977, exp. I6I, ff. I33.

57. Obra póstuma de Jorge Alberto Manrique denominada "La ciudad de México a través de los siglos."

58. Jorge Alberto Manrique y Teresa del Conde, Una mujer en el arte mexicano. Memorias de 
4. Jorge Alberto Manrique y Luis Carlos Emerich, 30 años de la Galería Pecanins, 1995. Foto: Paolo Gori. Archivo personal del autor.

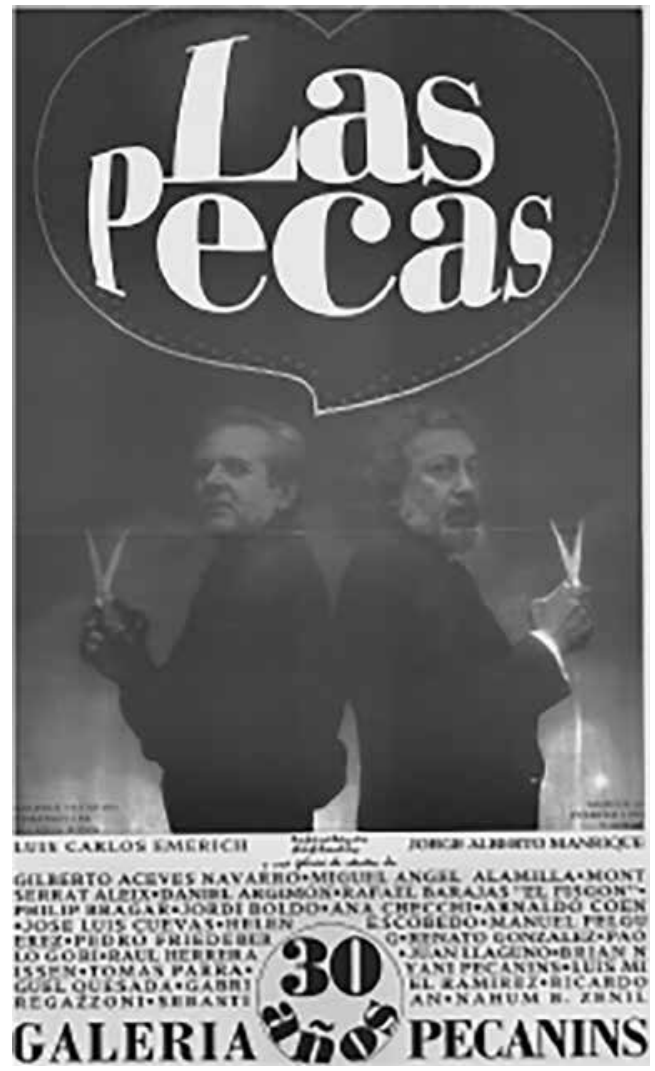

co de la Galería de Arte Mexicano al Instituto. Donación que se hizo pública en la prensa el i9 de marzo de 1975.59

Más adelante le encargaron la Guía de Historiografia al fundarse en 1976 el Sistema de Universidad Abierta de la UNAM.

Inés Amor (México: Universidad Nacional Autónoma de México-Instituto de Investigaciones Estéticas, 2005 [I ed. 1987]), IO-I5.

59. AHIIE, caja 9, exp. I57, ff. I-2. Dentro de las donaciones en su administración destacan las siguientes: Margarita Latapí viuda de Manuel Toussaint donó en 1976 el archivo personal de papeles, fichas, noticias, documentos, fotografías y manuscritos del maestro. Véase el AHIIE, caja 9 , exp. I6I, ff. I-2. El abogado José Miguel Quintana donó al IIE negativos de las lápidas funerarias, mismas que se resguardaron en el Archivo Fotográfico del Instituto. Véase el AHIIE, caja 9, exp. I62, ff. I-2. En 1979 Kati Horna donó cerca de mil fotografías de la Ciudad Universitaria, materiales gráficos y folletos. Véase AHIIE, caja 9, exp. I63, ff. 5. 
DOI: http://dx.doi.org/10.22201/iie.18703062e.2017.1.2599

296

MIGUEL ÁNGEL ROSAS

\section{Espacio Escultórico}

La idea del Jardín de esculturas, posteriormente denominado Espacio Escultórico surgió de la Coordinación de Humanidades de la Universidad en 1977, a cuyo cargo se encontraba Jorge Carpizo, quien en comunicación estrecha con artistas que laboraban en esa Coordinación y en el Instituto de Investigaciones Estéticas, presentó al rector Guillermo Soberón la idea inicial del proyecto. Desde su planteamiento se consideró acudir a seis artistas destacados, todos ellos miembros de la Universidad: Mathias Goeritz, Manuel Felguérez, Federico Silva, Helen Escobedo, Sebastián y Hersúa. ${ }^{60}$

El rector me pidió dar una asesoría técnica junto con Luis Cardoza y Aragón y Joaquín Sánchez MacGregor para hacer un jardín de esculturas cerca de la Sala Nezahualcóyotl [...] Yo asistí a las juntas, pero la obra fue de ellos. Se tomó la decisión de que las resoluciones fueran unánimes. De modo que ninguno fue autor de la obra, sino todos juntos. [...] Carpizo y el rector querían evitar que "paracaidistas" se apoderaran de aquellos terrenos. ${ }^{61}$

Dentro del círculo se pondrían las esculturas que los miembros del equipo realizaran individualmente. Luis Cardoza y Aragón los convenció de no hacerlo: "nada había que agregar, el círculo de módulos con la lava era la escultura" ${ }^{62}$

De esa forma se inauguró en 1979 el Espacio Escultórico y Luis Cardoza y Aragón fue el responsable de su forma definitiva.

\section{Conservación de monumentos}

Su interés por la arquitectura lo llevó a dar la batalla por la defensa del patrimonio histórico. Jorge Alberto Manrique fue miembro del Consejo de Monumentos Históricos Inmuebles, Comisión Consultiva Externa del Instituto $\mathrm{Na}$ cional de Antropología e Historia (1974); miembro de la Comisión Nacional

6o. Jorge Alberto Manrique, "Espacio Escultórico: obra abierta", en Arte y artistas mexicanos del siglo XX (México: Consejo Nacional para la Cultura y las Artes, 2000), I64.

6I. Renato González Mello relata que Jorge Alberto Manrique le platicó esa anécdota; véase el "Estudio preliminar" del libro: Luis Cardoza y Aragón, La nube y el reloj. Pintura mexicana contemporánea (México: Universidad Nacional Autónoma de México, 2003), I4.

62. Luis Cardoza y Aragón, La nube y el reloj, I5. 
de Zonas y Monumentos Artísticos, Instituto Nacional de Bellas Artes (1976); miembro de número del Comité Internacional de Monumentos y Sitios (ICOMos Mexicano), 3 de febrero de 1976; presidente de esa institución (I980-1988); miembro de la Junta de Honor (1988-200I) que le otorgaría el premio Federico Sescosse en 200I. Durante su gestión como cuarto presidente del Icomos Mexicano, ${ }^{63}$ reanudó los Simposios Interamericanos de Conservación del Patrimonio Monumental (del II al VIII). ${ }^{64}$

Dentro de la Comisión Nacional de México en la unesco para la salvaguarda de las ciudades históricas dentro del patrimonio mundial destaca su participación en la defensa del Palacio negro de Lecumberri. ${ }^{65}$

La defensa y rescate de Lecumberri se realizó cuatro años después de la creación de la Ley sobre monumentos y zonas arqueológicas, históricas y artísticas de 1972.

El I2 de enero de 1976 el periódico Excélsior publicó una entrevista que la reportera Magdalena Saldaña hizo a Eduardo Blanquel acerca de Lecumberri, en la cual se oponía a la destrucción de la Penitenciaría. Acudió a Jorge Alberto Manrique, que era entonces director del Instituto de Investigaciones Estéticas, "Yo envié al regente de la Ciudad de México Octavio Sentíes una carta, exponiéndole las razones por las que Lecumberri no debía ser destruido. Después

63. La lista de los primeros siete presidentes de icomos es la siguiente: José Villagrán García (1965-1976), Jorge Medellín (1976-1979), Luis Ortiz Macedo (1979-1980), Jorge Alberto Manrique (I98I-I988), Alberto González Pozo (I988-I99I), Carlos Flores Marini (I99I-I997), Ramón Bonfil Castro (1997-2003), quien instituye el premio Federico Sescosse en 2000.

64. El II tuvo lugar en Morelia, Michoacán (198I), el III en Trinidad, Tlaxcala (1982), el IV en Tepoztlán, Estado de México (1983), el V en Jalapa de Enríquez, Veracruz (1984), el VI en Cuernavaca, Morelos (1985), el VII en Puebla, Puebla (1986) y por último el VIII en Mérida, Yucatán (1987).

65. Es importante mencionar las siguientes batallas a favor de la conservación de: la capilla de la Concepción en Azcapotzalco, Ciudad de México; el coro y de los órganos monumentales de la Catedral de México; la cárcel de Lecumberri (ahora Archivo General de la Nación); los barrios ante la construcción de la mega plaza en Monterrey; las casas en centros históricos en Querétaro; las bardas atriales en el convento de San Diego en Cuautla y zona de Cacaxtla; Zócalo, la zona del Templo Mayor, el Barrio de San Ángel y el Barrio de Coyoacán de la Ciudad de México; el panteón de Jalapa; la Plaza del Baratillo en Guanajuato; el Barrio de San Juan de Dios en Guadalajara; la zona del malecón en Veracruz; así como contra los daños al Archivo General de la Nación en Palacio Nacional; contra la alteración la casa de Frida Kahlo; la destrucción inminente del Arco de Loreto en la ciudad de Puebla; de las casas de la Compañía Real del Monte (Monumento frente a la iglesia de San Juan Bautista, Coyoacán, Ciudad de México), y en pro de la salvaguarda de los monumentos en peligro por la construcción de la línea 8 del metro en la Ciudad de México. 
DOI: http://dx.doi.org/10.22201/iie.18703062e.2017.1.2599

298

MIGUEL ÁNGEL ROSAS

de diez días de no obtener respuesta publiqué esa carta en varios periódicos, entonces todo sucedió." 66

El dictamen lo realizó Flavio Salamanca, jefe del Departamento de Arquitectura, Instituto Nacional de Bellas Artes:

Lecumberri fue la primera construcción carcelaria de Latinoamérica realizada según un programa científico moderno. Fue además una de las pocas grandes obras porfirianas realizadas íntegramente por mexicanos. [...] Se resuelve conservar el edificio porque constituye por sí sólo un documento de gran importancia, testimonio histórico de toda una época ${ }^{67}$

Sergio Galindo, director del Instituto Nacional de Bellas Artes, estima que por ningún motivo se debe destruir el edificio que ocupa la Penitenciaría de México. ${ }^{68}$ "El hecho es que, contra todas sus reticencias, el presidente Echeverría, en la última de nuestras reuniones en Los Pinos, dijo: 'Detesto Lecumberri, pero, si ustedes que saben dicen que hay que conservarlo, conservémoslo."'69

Para salvaguardar el inmueble formaría parte de la SEP mientras que el INBA proporcionaría la asesoría necesaria respecto al nuevo uso que se daría al mismo. Después del rescate del Palacio, se debe al historiador Jesús Reyes Heroles, entonces secretario de Gobernación, la idea de convertir Lecumberri en la sede del Archivo General de la Nación. Para realizar la obra se contó con el proyecto del arquitecto Jorge L. Medellín y con la asesoría de la historiadora Alejandra Moreno Toscano. ${ }^{70}$ El decreto del 27 de mayo de 1977 destinó, para ese uso, el antiguo Palacio de Lecumberri.

En marzo de 198I la República italiana reconoce públicamente los logros en el campo de las artes a Jorge Alberto Manrique otorgándole la distinción honorífica Comendador de la Orden del Mérito.

66. Jorge Alberto Manrique, Lecumberri: un palacio lleno de historia (México: Secretaría de Gobernación-Archivo General de la Nación, 1994), 89-9I.

67. AHIIE, sección: Conservación de Monumentos, caja 2, año 1976-1977, exp. I40, ff. I53.

68. AHIIE, sección: Conservación de Monumentos, caja 2, año I976-I977, exp. I40, ff. 65.

69. Manrique, Lecumberri, 90.

70. La primera propuesta consistió en trasladar a ese espacio la Hemeroteca Nacional. 


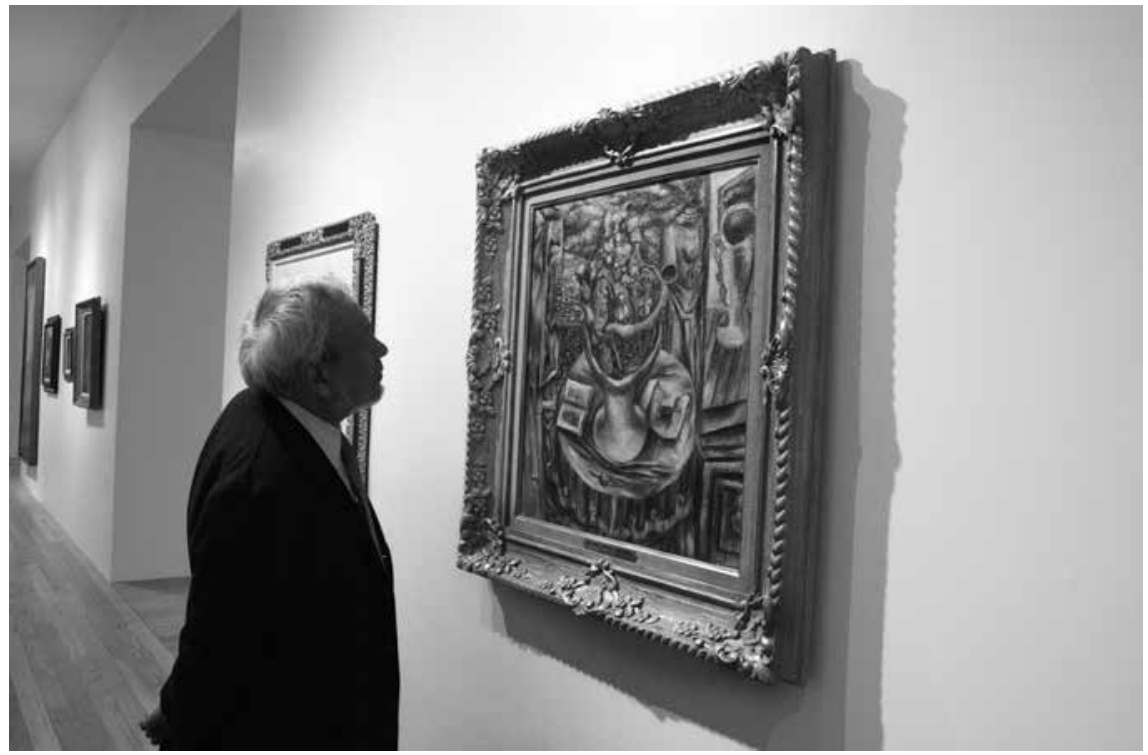

5. Jorge Alberto Manrique ante la obra Eco del mar (1945) de Alfonso Michel, 20II. Foto: Miguel Ángel Rosas. Archivo personal del autor.

\section{Museo Nacional de Arte}

"La idea de crear el Museo Nacional de Arte es muy vieja y surgió hace tres sexenios. Se empezó a considerar la necesidad de crear un museo general de arte que México aún no tenía. [...] y que presentara una visión completa del arte mexicano." ${ }^{1}$

El I4 de julio de 1981 mediante un decreto presidencial se determinó que el Museo Nacional se alojara en el antiguo Palacio de la Secretaría de Comunicaciones y Obras Públicas. Para ello se creó el I2 de octubre el Consejo de Fundación del Museo Nacional, "Estaba conformado por Raquel Tibol, Ser-

7I. Entrevista a Jorge Alberto Manrique por Mercedes García Ocejo, "El museo como disparadero", El Heraldo de México, I de julio de 1982 (encabezado). Archivo Histórico, Munal-inba. "En el programa de la Dirección de Artes Plásticas de 1978, durante la gestión del presidente José López Portillo, se incluyó el Proyecto Museo Nacional de las Artes Plásticas —luego sería denominado Museo Nacional de Pintura y finalmente llamado Museo Nacional de Arte", en Jennifer Rosado Solís, "El proyecto MUNAL 2000. Una respuesta trascendente a la demanda nacional de un proyecto museológico-curatorial”, tesis inédita (México: ENCRYM, 2015), 50. 
gio Pitol, Carlos Monsiváis, Mariano López Castro, Juan José Bremer y Jorge Alberto Manrique." ${ }^{2}$ Fueron muchas las reuniones en las que se discutió la importancia del proyecto y las características que debía tener. ${ }^{73}$ México necesitaba reflexionar su historia en un museo que le permitiera al espectador tener una visión completa del proceso artístico de nuestro país.

Fernando Solana, secretario de Educación Pública, invitó a Jorge Alberto Manrique como director fundador y a Helen Escobedo como directora técnica. ${ }^{74}$ Apoyados por un equipo especializado, en cuatro meses crearían el Museo Nacional de Arte (Munal). ${ }^{75}$

El equipo del museo entró a laborar el 3 de marzo de i98 I cuando el Archivo General de la Nación no acababa de trasladarse a su nueva sede en Lecumberri.

La obra de restauración arquitectónica estuvo a cargo de la Comisión para la Construcción de Escuelas (CAPFCE) bajo la supervisión de la Dirección de Arquitectura y Conservación del Patrimonio del Instituto Nacional de Bellas Artes. La restauración de los elementos decorativos [...] fue responsabilidad del Centro Nacional de Conservación de Obras Artísticas del propio Instituto. [...] El museo contaba con un fondo teóricamente disponible [...] esa colección estaba de alguna manera dispersa en oficinas, bodegas y dependencias diversas y fue una complicada labor el recuperarla [...] Ese fondo, sin embargo, no era bastante para alcanzar la idea de síntesis que se pretendía, de modo que hubo que trasladar [...] obra en depósito que se encontraba en otros museos. Los préstamos particulares se hicieron con opción de compra, pero la difícil situación económica [...] canceló totalmente la posibilidad de aumentar el acervo por adquisiciones. ${ }^{76}$

72. Rosado Solís, "El proyecto Munal 2000", 5 I.

73. Rosado Solís, "El proyecto Munal 2000", 54.

74. El maestro Jorge Alberto Manrique fue el director fundador, institución que encabezó entre el I3 de abril de i982 y el i de marzo de 1983.

75. El equipo quedó conformado de la siguiente manera: director del Museo Nacional de Arte: Jorge Alberto Manrique; directora técnica: Helen Escobedo; subdirectora técnica: Miriam Kaiser; investigación y documentación: Juana Gutiérrez; curaduría: Arturo Casado Navarro; registro de obra: Lourdes Cué; museografía: Constantino Lameiras; relaciones públicas: Enrique Silva; actividades paralelas: Guadalupe Salcedo; servicios educativos: Cristina Stoupignan de Payán; administración: Carlos David Bretón. A la coordinadora de Servicios Educativos, Cristina Stoupignan de Payán, la apoyó Eloy Tarcisio, Mario Rangel Faz, Yolanda Mora, Mario Núñez, Jimena Manrique, Mari Carmen Tostado, Marco Barrera Bassols y Beatriz Novaro.

76. Jorge Alberto Manrique, "Un museo en un Palacio", en Juana Gutiérrez Haces, El Palacio de Comunicaciones (México: Azabache/Secretaría de Comunicaciones y Transportes, I99I), I92-I95. 
El museo tenía que estar listo el 23 de julio para albergar las reuniones del Congreso Internacional de Secretarios y Ministros de Cultura, unesco, que se celebraría el día 25 .

El Museo Nacional de Arte se inauguró el 25 de julio de 1982 a las 7 pm; ocho días después de que Jorge Alberto Manrique cumpliera 46 años.

El Munal abrió sus puertas con un acervo de I,I24 obras procedentes de los museos y dependencias del Instituto Nacional de Bellas Artes y la Colección Sáenz de arte prehispánico. ${ }^{77}$ Las adquisiciones fueron las siguientes: "De los museos del Palacio de Bellas Artes (I), San Carlos (I63), Pinacoteca Virreinal de San Diego (34), Arte Moderno (I09), ${ }^{78}$ Carrillo Gil (I3), de la Dirección de Promoción Nacional (54), Oficina de Registro de Obras (449), de la Casa Leona Vicario (6), y de la Escuela de Diseño y Artesanías (295), dependencias todas ellas del Instituto Nacional de Bellas Artes."79

El ordenamiento de la exposición permanente se estructuraría a partir de dos recorridos. Uno cronológico (del arte prehispánico al moderno hasta la generación de Rufino Tamayo) en combinación con otro conceptual de producción artística que destacaba aspectos como las técnicas, la temática y los soportes haciendo patente el hecho artístico en el espectador. Un ordenamiento cronológico yuxtapuesto de otro conceptual permitiría un desplazamiento de la obra al sujeto, logrando con ello un "museo didáctico". Ésa fue la propuesta historicista de Manrique en el Munal.

77. La colección de Jacqueline y Josué Sáenz daría pie posteriormente al acervo permanente del Museo Amparo. Se contó además con obra del Museo de Antropología de Jalapa y del Museo del Templo Mayor de la Ciudad de México. Agradezco la entrevista sostenida con Vicente Rojo Cama.

78. En I982 el Inba ordena a la dirección del Museo de Arte Moderno, a cargo de José de Santiago, desgajar su colección constitutiva, y ceder Io9 obras de su acervo [...] A fin de fortalecer un nuevo proyecto sexenal: el Museo Nacional de Arte. Si bien las obras - entre ellas, 30 lienzos de José María Velasco, y otras 37 obras importantes de artistas como Rivera, Abraham Ángel, Siqueiros, Best Maugard y Ruelas — salieron con un oficio en "calidad de préstamo". Véase Daniel Garza Usabiaga, La máquina visual. Una revisión de las exposiciones del Museo de Arte Moderno 1964-1988 (México: Instituto Nacional de Bellas Artes-Consejo para la Cultura y las Artes-Museo de Arte Moderno, 20II), 229.

79. Áurea Ruiz de Gurza, "Introducción”, en Jaime Cuadriello, Catálogo comentado del acervo del Museo Nacional de Arte. Nueva España, t. I (México: Munal-Patronato del Munal/Universidad Nacional Autónoma de México-Instituto de Investigaciones Estéticas/Consejo Nacional para la Cultura y las Artes-Instituto Nacional de Bellas Artes, 1999), 23. Citado en Rosado Solís, "El proyecto Munal 2000”, 5 I. 
DOI: http://dx.doi.org/10.22201/iie.18703062e.2017.1.2599

Las salas permanentes del museo se conformaron de la siguiente manera:

Historia del Palacio de Comunicaciones, Arte prehispánico, Arte novohispano, ${ }^{80}$ La Academia, Artistas viajeros, Estampa, Pintura religiosa del siglo xIx, Pintura de historia, Grabado del siglo xix, Costumbrismo, Retrato y arte no académico, Escultura del siglo xix, Grabado del siglo xx, Velasco y sus contemporáneos, Pintura sentimental y literaria, Simbolismo ${ }^{81}$ Escuelas al aire libre, Escuela mexicana y Arte popular. Se contó además con una sala de Exposiciones temporales. ${ }^{82}$

En su gestión se sucedieron cuatro exposiciones temporales: "Agustín Lazo (I898-1971)", muestra que inauguró el 5 de noviembre de 1982 como un homenaje nacional a los Contemporáneos, compuesta por óleos, acuarelas, dibujos y diseño escenográfico.

"José Manzo. Artista neoclásico (I789-1860)", muestra que se exhibió del I5 de marzo al 22 de mayo de 1983, conformada por una colección de dibujos que custodia la Pinacoteca de la Universidad Autónoma de Puebla.

En preparación dejó: "Frida Kahlo-Tina Modotti" (I de junio al 3I de agosto de 1983), exposición procedente de la Whitechapel Art Gallery de Londres y la Grey Art Gallery de la Universidad de Nueva York (1982) con obras pictóricas y fotográficas de estas artistas, y "José Clemente Orozco. Sainete, drama y barbarie. Centenario. I883-I983", en la cual se mostró la obra del artista como caricaturista en el contexto del porfiriato y la Revolución mexicana.

Manrique, al proponer un museo activo, estaba muy preocupado por las actividades educativas. En entrevista con Eloy Tarcisio refiere:

Con respecto al acercamiento al público, nosotros diseńamos una estrategia, para que los visitantes pudieran acercarse a las piezas, pero además entender la figura y la ideología planteada en el guión museológico de las salas. Pedimos a algunos escultores

80. "La sala se basaba fundamentalmente en la gran pintura virreinal, desde el primer manierismo de Andrés de la Concha y Echave Orio [...], el manierismo avanzado de Echave Ibía y Luis Juárez, la formidable pintura barroca de José Juárez [...] y la posterior de Correa y Villalpando, ya a finales del siglo xviII, hasta la elegante pintura dieciochesca de Ibarra y Cabrera. [...] Todo un amplio ciclo artístico y cultural de la Nueva España [...] que tiene un desarrollo independiente de Europa." Véase Jorge Alberto Manrique, Museo Nacional de Arte (México: Instituto Nacional de Bellas Artes-Secretaría de Educación Pública, 1982), I7 [catálogo original de fundación del Museo].

8I. Es la primera ocasión que se le da un protagonismo a dicha corriente artística.

82. Manrique, Museo Nacional de Arte, I9. 
6. Jorge Alberto Manrique ante la obra Après l'orgie (1909) de Fidencio Lucanor Nava, 20I6. (C) Rogelio Cuéllar.

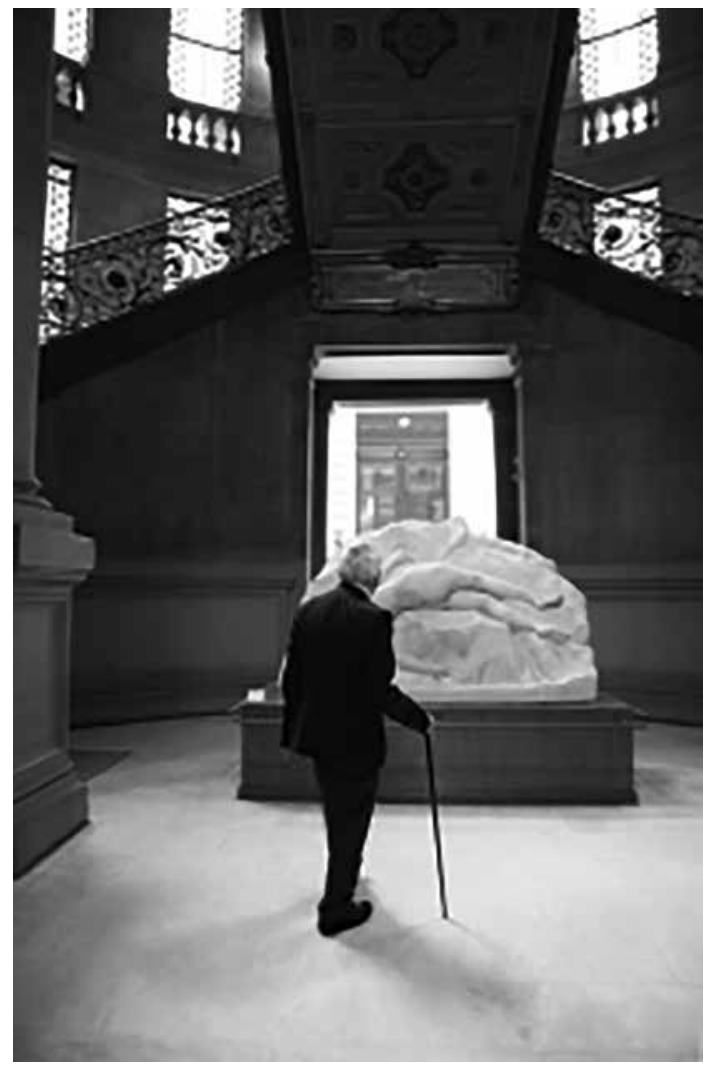

que nos prestaran obra que el público pudiera tocar. Ernesto Hume nos facilitó un par de esculturas originales que al tocarse emitían notas musicales. Ángela Gurría nos prestó La nube, entre otras, que eran originales que contaban con la autorización de los artistas para ser tocadas. ${ }^{83}$ Éramos un equipo que junto con la coordinadora de Servicios Educativos, Cristina Payán, diseñamos cómo entrar e interactuar con el público en las salas.

83. "Los talleres de prácticas artísticas los desarrollábamos a partir de la experiencia de la visita guiada o bien lo hacíamos a la inversa, primero pasaban al taller para darles indicaciones, como ejercicios con cuadros vivos, búsqueda de objetos dentro de las obras, identificación de las cualidades estéticas de las obras, entre otras." Agradezco las conversaciones sostenidas con Eloy Tarcisio los días 6 y 23 de febrero de 2017. 
DOI: http://dx.doi.org/10.22201/iie.18703062e.2017.1.2599

Los guías y nosotros trabajamos conjuntamente en el diseño de estrategias de comprensión de obra. ${ }^{84}$

El Munal contó con un cine-club que era parte del Departamento de Actividades Paralelas, coordinado por Guadalupe Salcedo. Los integrantes eran: Vicente Rojo Cama (22 años), Alfonso Cuarón (2I años) y Mariana Elizondo (20 años). ${ }^{85}$

El cine-club estaba a cargo de Alfonso Cuarón y lograron tener un cine de buena calidad con proyectores de $16 \mathrm{~mm}$. Él invitaba a los directores de las cintas y además era el proyeccionista. Se contó con la participación de: Alejandro Pelayo, José Luis García Agraz, Dora Guerra, Maryse Sistach, Luis Alcoriza, Marcela Fernández Violante, entre otros. ${ }^{86}$

Mariana Elizondo tenía a su cargo los recitales de poesía y conciertos de música; invitó a Pita Amor, Betsy Pecanins, al compositor Manuel Enríquez, al Cuarteto Latinoamericano, don Arcadio Hidalgo y el grupo Mono Blanco, entre otros.

Vicente Rojo Cama recuerda: "Manrique estaba muy abierto a cualquier tipo de manifestación que hiciera un museo vivo. En el Munal pudimos hacer cosas que no se hacían en otros museos, meter por primera vez grupos de rock y jazz, música contemporánea y electrónica." 87

Rojo Cama además de ser el asistente personal de Manrique tenía a su cargo el programa de conferencias relacionadas con las artes plásticas.

Lo destacable de la visión de Jorge Alberto Manrique fue, que además, aceptó un discurso alternativo al ofrecido desde la institución al permitir que el colectivo Atte. La Dirección interviniera la Plaza Tolsá mediante una serie de acciones performativas, "imágenes virtuales", como la instalación de i 000 cruces de madera el Día de Muertos de 1983. El colectivo apostó por el performance como medio para romper con las prácticas artísticas oficiales. Formaban parte de él: Carlos Somonte, María Guerra, Dominique Liquois, Vicente

84. El personal de visitas guiadas estaba compuesto por estudiantes de las carreras de Antropología y Antropología Social del INAH. Agradezco las conversaciones sostenidas con Eloy Tarcisio los días 6 y 23 de febrero de 2017.

85. El dato lo proporcionó Mariana Elizondo a quien agradezco la comunicación sostenida. El cine ocupó un lugar muy importante en la vida del maestro; no hay que olvidar que su hija Lorenza Manrique es diseñadora de producción y directora de arte de largometrajes.

86. Agradezco la conversación sostenida con Mariana Elizondo en febrero de 2017.

87. En entrevista con Vicente Rojo Cama el I4 de febrero de 2017. 
Rojo Cama, Eloy Tarcisio y Mario Rangel Faz (los tres últimos, integrantes del equipo del Munal).

Otra de las novedades fue la idea de una "bodega visitable", sin embargo, ésta quedó sólo en proyecto. ${ }^{88}$

En abril de 1983 llegó personal de Gobernación con unos camiones a llevarse las obras más importantes del Munal. Traían una carta firmada por el director del Instituto Nacional de Bellas Artes, Javier Barros Valero, y el secretario de Gobernación. El presidente Miguel de la Madrid a su llegada a la Presidencia solicitó los cuadros de José María Velasco, Rivera, Orozco, Cabrera, entre otros, para decorar la residencia oficial de los Pinos, las embajadas y las instituciones de gobierno. Vicente Rojo Cama y Miriam Kaiser les impidieron la entrada. ${ }^{89}$

Jorge Alberto Manrique negoció las obras solicitadas con Javier Barros Valero, ya que la lista era muy severa y las obras más importantes del Munal debían permanecer para el goce de todos y no el de unos cuantos.

La respuesta de la Presidencia fue la solicitud de renuncia de Jorge Alberto Manrique a la dirección del Munal. El maestro me decía: "Nunca me llevé bien con el poder."

El primer Munal fue una propuesta muy novedosa y funcionó; fue un museo abierto a partir de la idea de un visitante-partícipe. ${ }^{90}$

Jorge Alberto Manrique juntó un equipo de gente extraordinaria y había muchas ganas de divertirse. Él era muy culto, muy permisible, muy sensible,

88. El ı9 de julio de 1982 Jorge Alberto Manrique dirigió una carta al director general de Obras Públicas, el arquitecto Guillermo García Villavicencio con la petición de recuperar las esculturas Malgré tout (1898), de Jesús Fructuoso Contreras, Desespoir (1900), de Agustín L. Ocampo, Gladiador frigio (ca. I830) y Gladiador romano (ca. I830), de José María Labastida, de la Alameda central al Museo Nacional de Arte. La respuesta del director general de Obras fue en los siguientes términos: "Estamos anuentes para que se proceda al retiro de las piezas originales, siempre y cuando sean sustituidas por piezas idénticas. Esta Dirección a mi cargo, no contempla ningún presupuesto, para atender este problema, por lo que en caso de que fuera del interés de ustedes que se hiciera la sustitución [...] tendría que ser con cargo al propio presupuesto del Instituto Nacional de Bellas Artes." Véase la carta al C. Jorge Alberto Manrique respecto al traslado de las esculturas originales de la Alameda al Munal, 20 de septiembre de 1982 en el Archivo Histórico Museo Nacional de Arte, oficio número 1295 del Departamento del Distrito Federal-Dirección General de Obras Públicas. El traslado de las esculturas se realizó hasta 1986 y las reproducciones realizadas se vaciaron en bronce y se llevaron a cabo por el Centro Nacional de Conservación de Obras Artísticas del Instituto Nacional de Bellas Artes.

89. Agradezco la conversación sostenida con Eloy Tarcisio, Vicente Rojo Cama y Mariana Elizondo.

90. Entrevista con Vicente Rojo Cama. 
DOI: http://dx.doi.org/10.22201/iie.18703062e.2017.1.2599

después llegó Jorge Hernández Campos el segundo director del Munal y se perdió frescura, chispa. ${ }^{9}$

Paralelo a la dirección del Munal, 1982 es el año del proyecto de la enciclopedia Historia del Arte Mexicano en colaboración con la Secretaría de Educación Pública, el Instituto Nacional de Bellas Artes y la Editorial Salvat. ${ }^{92}$ El rigor académico y su carácter accesible se debieron a su coordinador general Jorge Alberto Manrique y $7 \mathrm{I}$ autores, expertos en sus respectivos temas conformaron la obra de 16 volúmenes. ${ }^{93}$

La enciclopedia está dividida en cuatro partes, cada una de las cuales comprende cuatro tomos de i6o páginas cada uno, lo que significa un total de 2,560 páginas. Los coordinadores por módulo fueron los siguientes: Beatriz de la Fuente (arte prehispánico), Elisa Vargas Lugo (arte colonial), Fausto Ramírez (arte del siglo XIX), Jorge Alberto Manrique (arte contemporáneo). La imagen fue parte fundamental de la obra, 13 ooo fotografías constituyeron el repertorio gráfico.

La Historia del Arte Mexicano constituyó un esfuerzo para poner a la vista el panorama completo de nuestro arte y hacer asequible, así, el conocimiento de las obras y, por ellas, de nuestra historia. Fue tan grande el éxito que la primera edición de 20000 ejemplares se agotó y daría paso a una segunda en 1986.

91. Entrevista con Mariana Elizondo.

92. La primera edición apareció originalmente en fascículos coleccionables de 1982, 1983 y 1984.

93. Colaboradores académicos: Esther Acevedo, Alberto Amador Sellerier, Concepción Amerlinck, Enrique X. de Anda Alanís, Eduardo Báez Macías, Elizabeth Baquedano, Clara Bargellini, Rebeca Barrera de Fraga, Ignacio Bernal, Arturo Casado Navarro, Rosa Casanova, Efraín Castro, Marcia Castro Leal, María Ester Ciancas, Jaime Cuadriello, Gustavo Curiel, Beatriz de la Fuente, Guadalupe de la Torre, Aurelio de los Reyes, Teresa del Conde, Rogelio Cuéllar, Marco Díaz, Clementina Díaz y de Ovando, Humberto Domínguez, Rita Eder, Estela Eguiarte, Elena I. Estrada de Gerlero, Martha Fernández, Marta Foncerrada de Molina, Elizabeth Fuentes, Emma Cecilia García, Elisa García Barragán, Paul Gendrop, Manuel González Galván, Juana Gutiérrez, Nelly Gutiérrez Solana, Horst Hartung, Lily Kassner, Nanda Leonardini, Sonia Lombardo de Ruiz, Jorge Alberto Manrique, Leonardo Manrique, Consuelo Maquívar, Amada Martínez, María Josefa Martínez del Río de Redo, Carlos Martínez Marín, Porfirio Martínez Peñaloza, Cristina Montoya, María Dolores Morales, Xavier Moyssén, Carlos Navarrete, Lorenzo Ochoa, Fausto Ramírez, Guillermina Ramírez Montes, Aurelio de los Reyes, Francisco Reyes Palma, Constantino Reyes Valerio, Ida Rodríguez Prampolini, Delmari Romero Keith, María del Carmen Ruiz Castañeda, Rogelio Ruiz Gomar, Marcela Salas, Otto Schöndube, Jenny Stoopen, Raquel Tibol, María Teresa Uriarte, Eloísa Uribe, Ernesto Vargas, Elisa Vargas Lugo, Eduardo de la Vega, Moisés Viñas. 
7. Jorge Alberto Manrique, 2016.

(C) Rogelio Cuéllar.

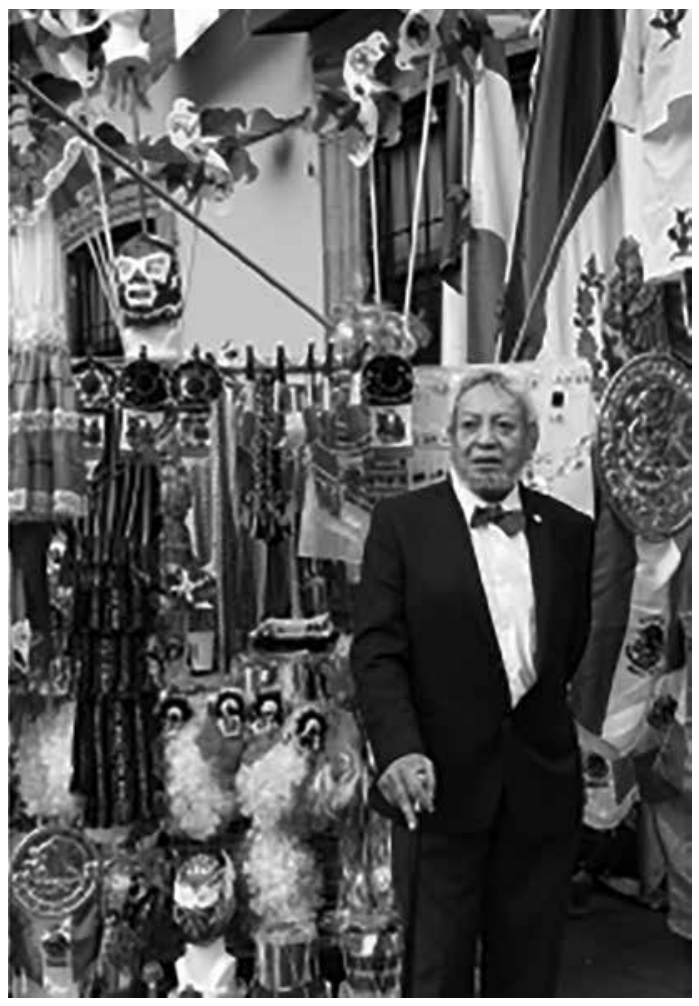

\section{Museo de Arte Moderno}

De febrero de 1987 a enero de 1988 Jorge Alberto Manrique dirigió el Museo de Arte Moderno. La propuesta era tener estrecho contacto con los jóvenes pintores para la donación y adquisiciones de obra; lo anterior con la finalidad de renovar la colección del museo con la generación de la nueva pintura mexicana y hacer que el MAM fuera realmente un museo de arte moderno.

Manrique tenía un particular interés en desarrollar nuevamente actividades paralelas intensas, tal como lo propició en el Munal. Juan Acha menciona: "Durante su dirección, se registró un incremento de las actividades difusoras, tales como las conferencias que fueron 22 en 1987." ${ }^{4}$

94. Juan Acha, Museo de Arte Moderno 25 años: 1964-1989 (México: Consejo Nacional para la Cultura y las Artes-Instituto Nacional de Bellas Artes-Banco Nacional de Obras y Servicios 
Uno de los proyectos que desafortunadamente no se pudo llevar a cabo — debido al corto tiempo de su administración — fue la construcción de las bodegas del museo.95

Se sucedieron 3I exposiciones temporales durante la gestión de Jorge Alberto Manrique: "Philip Bragar", "Ricardo Rocha", "Nahum B. Zenil", "Ismael Guardado", "Adolfo Patiño", "Kasuya Sakai", "José Vermeersch", "Luis Fernando Camino", "Nicolás Amoroso", "Víctor Flores Olea", "Rubén Vargas", "Marco Antonio Arteaga", "Oliverio Hinojosa", "Óscar Rodríguez", "Carmen Parra", fueron algunas de ellas, ${ }^{96} \sin$ embargo, la piedra de toque fue la sección de Espacios Alternativos del Salón Nacional de Artes Plásticas (SNAP), diciembre de 1987 a enero de 1988 .

La Dirección de Artes Plásticas del inba convocó al concurso de la segunda bienal de Espacios Alternativos el 13 de junio de 1987 con las siguientes bases: "Podrán participar todos los artistas o grupos de artistas interesados en la práctica de aquellas manifestaciones que salen de las maneras y soportes tra-

Públicos, S.N.C., 1989), 33. De las 22 conferencias, solamente se conservan dos en el Centro de Documentación del Museo de Arte Moderno; ambas relacionadas con Vicente Rojo. La consulta de dicho centro la realicé el mes de febrero de 2017.

95. Entrevista a Vicente Rojo Cama.

96. La lista completa de las exposiciones es la siguiente: "Philip Bragar. Tres décadas de trabajo en México", febrero-abril, 1987; “Ricardo Rocha, 1980-1986", febrero-abril, 1987; “México 9”, febreroabril, 1987; "Luis Fernando Camino; arte digital”, marzo-abril, 1987; "Nicolás Amoroso. Las horas que pasan”, abril-junio, 1987; "Cuerpo y movimiento. Fotografías de danza”, mayo-junio, 1987; "Víctor Flores Olea. Los trabajos y los días", mayo-julio, 1987; "Nahum B. Zenil, Yo también soy mexicano", mayo-julio, 1987; "Manuel Álvarez Bravo, Exposición fotográfica”, mayo-julio, I987; "Rubén Vargas, Tuércele el cuello al teléfono", junio-agosto, 1987; "Marco Antonio Arteaga, La caja de Pandora”, junio-agosto, 1987; "Oliverio Hinojosa, Al margen del silencio", julio-agosto, 1987; "Óscar Rodríguez, La ciudad... la noche”, julio-septiembre, 1987; "Imágenes traspuestas”, julio-septiembre, 1987; "Carmen Parra, La mariposa monarca”, julio-agosto, I987; "Xavier Meléndez, Geometrías transparentes”, agosto-octubre, 1987; "Ismael Guardado, Milungo oblongo", agosto-septiembre, 1987; "Para tanto oropel... tiene espinas el nopal. Lo mexicano de lo mexicano", septiembre-noviembre, 1987; "Adolfo Patiño, A los héroes de la patria”, septiembre-octubre, 1987; "Kasuya Sakai, Serie genroku”, octubre-noviembre, 1987; "Salvador Manzano, El espacio curvilíneo", octubre, 1987-enero, 1988; "Roberto Fabelo, Fragmentos vitales", octubre-diciembre, 1987; "Figura a figura", octubre-noviembre, 1987; "Olga Dondé, Germinante solar", octubrenoviembre, 1987; "XX aniversario grupo nuevos grabadores", noviembre-enero, 1988; "Encuentro de ceramistas contemporáneos de América Latina”, noviembre, 1987-enero 1988; "Carlos Santos, Altar de muertos", noviembre, 1987; "José Vermeersch", diciembre-enero, I988; "Salón Nacional de Artes Plásticas, Espacios alternativos", diciembre I987-enero 1988; "Grabado yugoslavo contemporáneo", diciembre de I987-enero de I988; "Xavier Girón, Pegaso”, diciembre I987-enero 1988. 
dicionales: ambientaciones, ensamblajes, instalaciones y montajes, arte objeto, multimedia, arte conceptual, arte correo y cualesquiera otras alternativas plásticas no tradicionales." 97

El jurado estuvo integrado por Hilda Campillo, artista visual y promotora cultural, Santiago Espinosa de los Monteros y Luis Rius Caso, investigadores y críticos de arte.

Se reunieron los días 29 y 30 de noviembre y del 7 al io de diciembre para emitir su fallo de lo que debía exponerse. Hubo 52 concursantes de los cuales aceptaron a 30 en una primera etapa de selección. La segunda consistió en hacer visitas a las piezas durante sus diferentes etapas de construcción. Dicha situación los hizo reconsiderar en algunos casos su evaluación debido al mayor o menor apego al proyecto original. ${ }^{98}$

Los tres premiados fueron: I) la presentación colectiva de Mauricio Maillé, Gabriel Orozco y Mauricio Rocha, titulada Apuntalamiento de un espacio (reflexión sobre la situación actual del arte);99 2) Marco Aurelio Montes Esquivel, con el trabajo titulado La tierra prometida, evocando los trágicos sucesos de los indocumentados fallecidos en un vagón de ferrocarril; y 3) Kiyoto Ota Okuzawa con su instalación Sin título.

Debido a la alta calidad de otros trabajos, el jurado decidió otorgar dos menciones honoríficas. Corresponde a Gerry Lejtik, por su ambientación titulada Nocturno a la alcoba. La segunda a César Martínez, por su trabajo titulado Explorarte. ${ }^{\text {Ioo }}$

La exposición se abrió al público el Io de diciembre de 1987 con 30 obras, producto de los demás participantes de la bienal. El espacio destinado fue la Sala III que se ubicaba en el primer piso del Museo de Arte Moderno.

Atte. La Dirección se presentó con la instalación: Voyovasvengovienes, consistía de una bandera tricolor donde se colocó en su sección blanquecina un águila

97. Novedades, I3 de junio de 1987, sección de cultura.

98. Carta de Hilda Campillo, Santiago Espinosa de los Monteros y Luis Rius, Io de diciembre de 1987. Museo de Arte Moderno-Centro de documentación, carpeta: Espacios Alternativos, Rolando de la Rosa. 4I/I3I-2.

99. "Consistía en un andamiaje de madera burda a la manera de aquellos que habían surgido en las calles de la ciudad en los meses consecutivos al terremoto, pero en este caso parecía sostener la estructura misma del museo." Véase Olivier Debroise, "Puertos de entrada: El arte mexicano se globaliza 1987-1992", en La era de la discrepancia. Arte y cultura visual en México, 1968-1997 (México: Universidad Nacional Autónoma de México, 2007), 332.

ıoo. Carta de Hilda Campillo. 
DOI: http://dx.doi.org/10.22201/iie.18703062e.2017.1.2599

$3 \mathrm{IO}$

MIGUEL ÁNGEL ROSAS

muerta bańada con chapopote, unos frascos con cenizas humanas para recrear la idea de un cementerio y una instalación de fuego con combustible líquido que se iba a prender en la inauguración. Todo ello para plantear con símbolos claros y el sentido de pertenencia de lo mexicano y generar una reflexión intelectual y profunda de la situación en nuestro país. El animal explotó por su estado de descomposición tres días después.

"El grupo que se hizo llamar La Compañía Luz y Fuerza, constituido por Rubén Ortiz Torres, Diego Toledo y Emmanuel Lubezki, por su parte, presentó la instalación Todo lo que no es tradición es plagio: un terreno pedregoso sembrado de monitores y dominado por una columna griega quebrada."

La instalación El real templo real de Rolando de la Rosa se trataba de un conjunto de tres secciones o altares en los que el autor montaba sobre imágenes religiosas iconos de la cultura de masas. ${ }^{102}$ Marilyn Monroe era la Virgen de Guadalupe y Pedro Infante, Jesucristo. El niño Jesús apareció con la cara del artista, sombrero de charro, guante boxeador y balón de futbol. En vez del Sagrado Corazón, De la Rosa colocó una botella de licor con telarañas $y$, finalmente, la bandera nacional pisada con dos botas texanas.

La obra de Rolando de la Rosa no era especialmente memorable en cuanto a su factura plástica - con una crítica poco reflexiva—, pero sí provocadora.

El sábado 23 de enero de 1988 - casi un mes y medio después de la inauguración- un grupo de manifestantes convocado por el Comité Nacional ProVida (presidido por Jorge Serrano Limón) y la Unión Nacional Sinarquista (por medio de su jefe Víctor Atilano Gómez) — dos grupos de ultraderecha católica- irrumpió en las instalaciones del Museo de Arte Moderno. ${ }^{103}$

Nosotros exigimos que en esos momentos se retirara la pieza y el cierre de la exposición [...] consideramos que los responsables directos son la SEP y el INBA, además del mismo director del Museo de Arte Moderno. [...] Inmediatamente procedió todo el contingente de alrededor de cuatro mil personas a pasar dentro del recinto. Allí,

IоI. Olivier Debroise, "Puertos de entrada: El arte mexicano se globaliza 1987-1992", en La era de la discrepancia. Arte y cultura visual en México 1968-1997 (México: Universidad Nacional Autónoma de México, 2007), 332.

IO2. El altar principal era la "Virgen-Marilyn", el segundo "Cristo-Infante", el tercer y último "futbol-sexo-alcohol."

I03. Se unirían a dicha protesta la Universidad La Salle con los colegios católicos, la Unión Nacional Estudiantil, el Grupo Acción, el Grupo Metas, la Asociación Juvenil Naucalpense, la Unión de Escuelas Particulares de Tlalnepantla y el Instituto Juventud de Santa María la Ribera. 


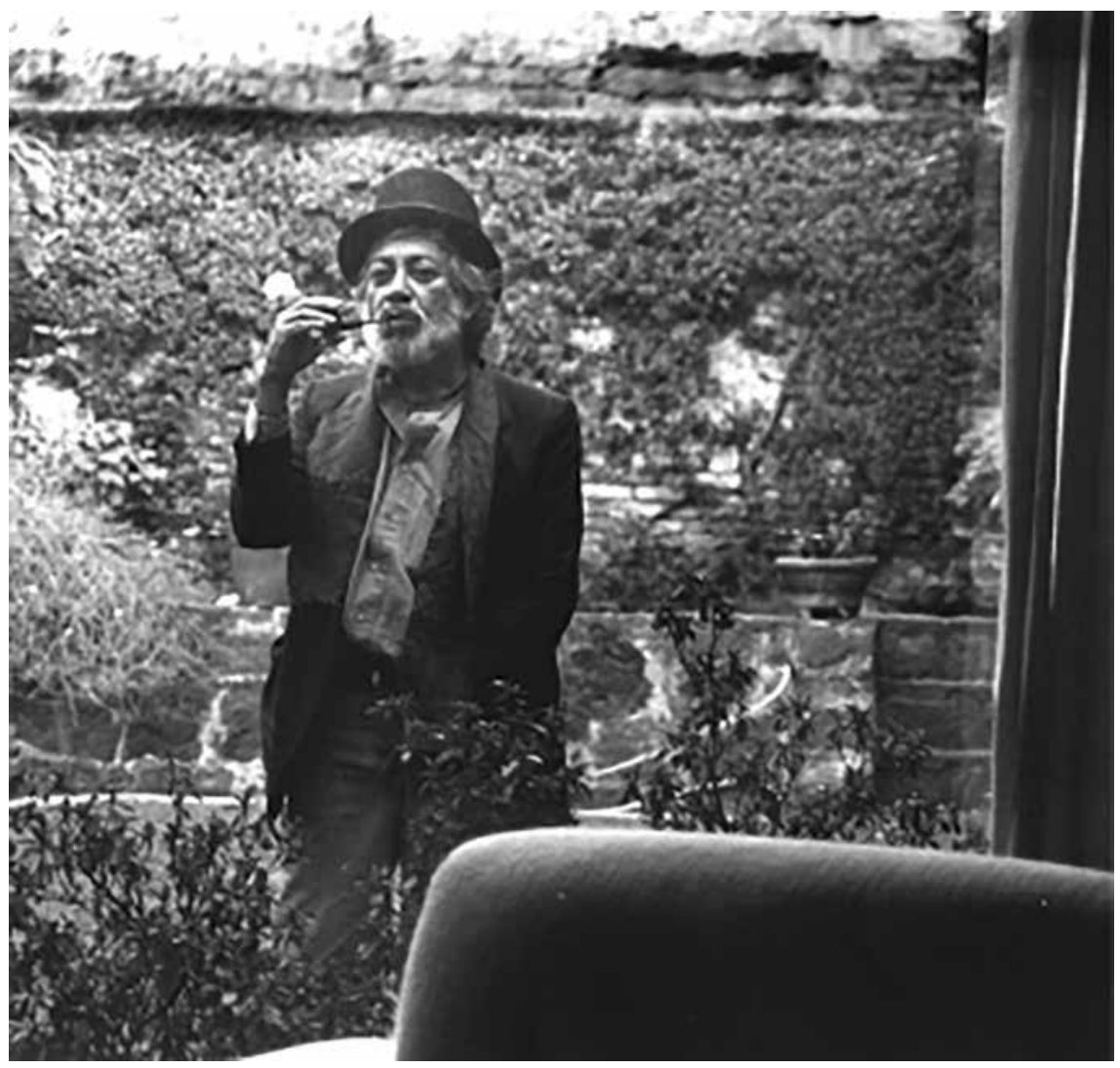

8. Jorge Alberto Manrique, 1998. Foto: Sebastián M. Coronel. Archivo Fotográfico Manuel Toussaint, IE-UNAM.

con cantos guadalupanos, vivas a Cristo Rey, vivas a México y el Himno Nacional, se rezó un primer rosario. Llegó el señor Antonio Lucke, subdirector del museo, manifestamos: ¡Esto no es arte!, es una agresión a nuestros valores cristianos, ¡esto no es arte!, es una agresión a nuestros valores patrios. Inmediatamente rezamos un segundo rosario. [...] El pueblo católico no podía permitir que se estuviera exhibiendo las profanaciones a nuestra señora de Guadalupe, nuestro señor Jesucristo y nuestros valores nacionales. [...] Terminó este evento con el Himno Cristo Rey, el himno Guadalupano, se rezó un tercer rosario y el Himno Nacional. [...] Una vez desmontada la obra solicitamos al Secretario de Educación Pública la renuncia del 
subsecretario de Cultura Martín Reyes Vayassade como del director del InBa Manuel de la Cera y la del director del Museo de Arte Moderno, Jorge Alberto Manrique. [...] La Santísima Virgen de Guadalupe es símbolo de castidad, de la pureza y el expositor le puso imagen de prostituta." 104

Al ceder a esta presión sectaria, el director general del Instituto Nacional de Bellas Artes, Manuel de la Cera, decidió destituir a Jorge Alberto Manrique como director del Museo de Arte Moderno.

La carta de renuncia la presentó el 25 de febrero de 1988 en los siguientes términos: "Le ruego reciba por este conducto mi renuncia formal como Director del Museo de Arte Moderno [...] No puedo dejar de expresarle que, cualquiera que sea el juicio que se tenga sobre mi gestión, considero lamentable que se me separe del cargo en la actual y precisa circunstancia: inevitablemente esta decisión se interpretará como un espaldarazo a los atacadores de museos y a las presiones de las fuerzas más obscuras de la comunidad."'os

El incidente generó un debate público sobre la libertad de expresión y las intenciones de grupos conservadores moralistas, por regular el espacio público.$^{106}$ La Unión Nacional Sinarquista convocó a sus militantes y al pueblo católico de México a una marcha de desagravio el domingo 28 de febrero a las 9 horas. Marcharon aproximadamente 500000 personas del Zócalo a la Basílica de Guadalupe, donde a las I2 horas el cardenal Ernesto Corripio Ahumada ofició una misa de desagravio para reparar la profanación de que fueran objeto la Virgen de Guadalupe y el señor Jesucristo por la sacrílega exposición del Museo de Arte Moderno. ${ }^{107}$

En respuesta, hubo una marcha por la libertad de expresión en la Plaza de Santo Domingo. El grupo Atte. La Dirección realizó la acción Cállensen.

En un documento firmado por un centenar de artistas e intelectuales se señala que la renuncia pedida a Jorge Alberto Manrique no es más "que una

I04. Versión de Víctor Atilano Gómez jefe de la Unión Nacional Sinarquista. Museo de Arte Moderno-Centro de documentación, carpeta: Espacios Alternativos, Rolando de la Rosa. 4I/I3I-2

I05. Víctor Atilano Gómez, Museo de Arte Moderno-Centro de documentación carpeta: Espacios Alternativos, Rolando de la Rosa. 4I/13I-2.

I06. Víctor Atilano Gómez, Museo de Arte Moderno-Centro de documentación, carpeta: Espacios Alternativos, Rolando de la Rosa. 4I/13I-7.

I07. Museo de Arte Moderno-Centro de documentación, carpeta: Espacios Alternativos Rolando de la Rosa, 4I/13I-5 (Quehacer político, núm. 333, 8 de febrero de I988). 
presión ejercida por grupos reaccionarios" ${ }^{108}$ El texto del documento es el siguiente:

La decisión de las autoridades de propiciar la renuncia del maestro Jorge Alberto Manrique como director del Museo de Arte Moderno nos causa una profunda indignación [...] Los firmantes, productores y promotores de arte, exigimos a las autoridades que el maestro Manrique sea de inmediato restituido en su puesto [...] el atentar contra la libertad de expresión artística, contra los recintos culturales sienta un precedente nefasto para la cultura nacional. El maestro Manrique es un reconocido profesional, intelectual, promotor cultural y estudioso de las artes plásticas con proyección internacional. ${ }^{\text {Io9 }}$

Paralelo a esto hubo una demanda judicial por parte de la Unión Nacional de Padres de Familia contra Rolando de la Rosa por el delito de "ultrajes a las insignias nacionales" con el número de expediente 779. Por su parte, Rolando de la Rosa se escondió ante el alboroto y no dio la cara. ${ }^{\text {IIO }}$

El Comité Nacional Pro-Vida y la Unión Nacional Sinarquista convocaron a una cruzada del rosario en museos, cines y teatros. El I5 de enero de I988 consiguieron el cierre de las galerías A y B del Auditorio Nacional a raíz de la exposición — auspiciada por el Instituto Nacional de Bellas Artes- de los cristos de Gustavo Monroy. Las notas de prensa hicieron referencia a los "grotescos óleos presentando a Cristo en situaciones eróticas". ${ }^{\text {II }}$ Para los grupos católicos el hecho de que Manuel Alegría, director general del inmueble hubiera accedido a presentar la obra de Monroy representaba un atentado más a la religión católica.

Jesusa Rodríguez sufrió amenazas, robo de equipo y vestuario por la puesta en escena de Concilio de amor (1988), adaptación de una obra de Oskar Paniz-

I08. Entre los firmantes se encontraban: Manuel Felguérez, Vicente Rojo, Teresa del Conde, Carlos Monsiváis, Olga Harmony, Fernando de Ita, Margie Bermejo, Martha de la Lama, Juan García Ponce, Ida Rodríguez Prampolini, Francisco Castro Leñero, Gabriel Macotela, Hilda Campillo, Olivier Debroise, Mercedes Oteyza, Bulmaro Castellanos, Javier Esqueda, Mónica Mansour, Marisa Magallón, Salvador Toussaint, Lucila Rousset, Carolia Paniagua, Magali Lara, Rafael Barajas (El Fisgón).

I09. La Jornada, 28 de febrero de 1988.

IIO. Entrevista a J.A.M.

III. Museo de Arte Moderno-Centro de documentación, carpeta: Espacios Alternativos, Rolando de la Rosa, 4I/13I-5 (Quehacer Politico, núm. 333, 8 de febrero de i988) I3I-5. 
DOI: http://dx.doi.org/10.22201/iie.18703062e.2017.1.2599

za, que hacía una sátira de las principales figuras de la religión cristiana en el contexto de la epidemia del sida. El grupo Divas, A.C., de Jesusa Rodríguez sólo pudo continuar su temporada con la vigilancia de patrullas a la entrada del Foro Shakespeare donde se estaba presentando. ${ }^{\text {II }}$

Jorge Alberto Manrique, Jesusa Rodríguez y Gustavo Monroy fueron quienes con sus acciones abrieron brecha a la libertad de expresión de este país.

Un año después del incidente, entre 1989 y 1992 Teresa del Conde y Jorge Alberto Manrique se escriben las Cartas absurdas. Originalmente irían ilustradas con un par de imágenes de Lorenza Manrique - hija de Jorge Alberto. Ellos aparecen de espaldas uno al otro, pose semejante a la que Paolo Gori utiliza en I995 para el cartel del 30 aniversario de la Galería Pecanins, en un frente a frente intelectual entre Luis Carlos Emerich y Jorge Alberto Manrique. Fueron dos fotografías que Lorenza les tomó para la edición de dicho libro; aún siguen inéditas en el archivo del maestro. El diseńo de portada fue de Rafael López Castro.

\section{Premios y distinciones}

El 24 de septiembre de I99I, a Jorge Alberto Manrique se le aceptó como Miembro de Número de la Academia de Artes. El discurso de ingreso se centró en el arte joven "Artistas en tránsito, México 1980-1995". La respuesta la otorgó Manuel Felguérez.

En 1992 se le otorgó el Premio Universidad Nacional en el Área de Docencia en Humanidades bajo la propuesta de la Dirección de la Facultad de Filosofía y Letras. El discurso de recepción estuvo a cargo del rector José Sarukhán. El evento se llevó a cabo en solemne ceremonia en el auditorio Alfonso Reyes de la Torre de Humanidades en Ciudad Universitaria. ${ }^{\mathrm{II} 3}$ Cuando el maestro Manrique recibió el Premio, entre un grupo de discípulos, nació la inquietud de reunir en un corpus toda su obra escrita dando lugar a los cinco tomos que

II2. Escrita por Oskar Panizza en I894 y ambientada en la corte papal de los Borgia, esta obra es la más deliciosa obra satírico-religiosa: un Dios Padre senil y cansado, aturdido por las voces aduladoras de los ángeles; un Jesús indolente, derrotado y en decadencia; y una María obsesionada por el sexo y cansada de ser virgen, decidirán pedir los servicios del Diablo para desatar una plaga que castigue a los hombres por sus excesos.

II3. Manrique y Del Conde, Cartas absurdas, I63. 
componen la obra: Una visión del arte y de la historia. ${ }^{\mathrm{II}}$ Paralelo a ello se realizó una exposición con retratos suyos elaborados por diversos artistas.

En 1996 ingresó a la Academia Mexicana de Ciencias y al Seminario de Problemas Científicos y Filosóficos.

A finales de los años noventa un daño cerebral lo privó de la facilidad del habla; Jorge Alberto Manrique sufrió un prolongado y difícil proceso de recuperación. Pese a ello, el 2I de junio de 2000 obtuvo la distinción de Investigador Emérito de la unam vía el Consejo Universitario: "Ser maestro emérito tiene un significado muy, muy grande para mí. La Universidad ha sido mi vida, los maestros, los alumnos, los amigos, todo lo tengo ahí."IIs

La Universidad fue para el maestro Manrique su casa. Él le dedicó un gran pedazo de vida a la Universidad y ella se lo supo reconocer.

En diciembre de 2005 Jorge Alberto Manrique recibió el Premio Nacional de Ciencias y Artes, máxima distinción que el gobierno federal otorga a los mexicanos que por su trayectoria, trabajos y obras han contribuido al progreso de la ciencia y al enriquecimiento del acervo cultural del país. En el Salón Adolfo López Mateos en la residencia oficial de Los Pinos, Carlos Monsiváis fue narrador de aquella noche.

\section{Homenaje de 80 años}

Los días 6 y 7 de septiembre de 20I6, el Instituto de Investigaciones Estéticas de la UnAM, en colaboración con el Instituto Nacional de Bellas Artes (INBA),

II4. Jorge Alberto Manrique, Una visión del arte y de la historia, t. I (México: Universidad Nacional Autónoma de México-Instituto de Investigaciones Estéticas, 2000), II. La compilación estuvo a cargo de Martha Fernández y Margarito Sandoval con la colaboración de Edgardo Ganado Kim y Georgina Alfaro González, Silvia Chacón González, Luis Gerardo García Rosales, Josefina Hernández Garibaldi, María Guadalupe López Bravo, Norma Márquez de Mota, Tanya Ortiz Galicia, Pedro Agustín Salmerón Sanginés y María Elena Terrés. El proyecto se dividió en dos etapas. En una primera etapa reunió los trabajos de investigación que el maestro escribió entre los ańos 1960 y 1996. El proyecto comenzó en 1994 con Gustavo Curiel, Martha Fernández y Nelly Sigaut, esta primera etapa concluyó en 1999 con la entrega de 150 textos reunidos en cinco volúmenes. La segunda parte del proyecto se basa en sus artículos de divulgación, es decir, los ensayos hemerográficos, proyecto en el que me tocó participar con Jorge Alberto Manrique gracias a una beca que me otorgó el Sistema Nacional de Investigadores SNI-CONACYT (2005-2008) como ayudante de investigador nacional nivel III. Se trabajaron más de 515 artículos periodísticos, previa compilación de Martha Fernández y Margarito Sandoval (material inédito).

II5. Concepción Salcedo Meza, "Expresiones... por escrito", I55. 
mediante el Museo Nacional de Arte y el Museo de Arte Moderno, rindieron homenaje con una serie de mesas de análisis sobre la vida, la obra y las aportaciones del maestro en los diferentes campos del conocimiento que investigó. Así como con dos pequeñas exposiciones de carácter documental. ${ }^{116} \mathrm{La} \mathrm{Fa}-$ cultad de Filosofía y Letras, UnAM, le realizó otro homenaje el io de octubre.

\section{Funeral, 2 de noviembre de 2016 - "Día de Muertos"}

El 2 de noviembre a las 8 am el maestro murió. Su velatorio fue en los funerales J. García López en Coyoacán. Recuerdo que siempre pasábamos por ahí cuando regresábamos del Instituto, y una ocasión el maestro me dijo: "cuando muera quiero que me velen aquí, no quiero que sea en Gayosso, quiero que sea cerca de mi casa”..., y así fue. Él siempre vivió rodeado de cartonerías, calacas, diablos y máscaras. Fue el mejor día para él.

El maestro Manrique fue un hombre que supo vivir, vivió intensamente, aún después de haber sufrido una afasia que padeció por 20 años. El daño cerebral afectó la parte izquierda de su cerebro y tuvo que volver a empezar, reaprendió a leer, escribir y hablar. Recuerdo cuando me decía: "tú conociste al león desdentado"... en realidad, conocí al ser humano. El maestro fue un hombre generoso que siempre estuvo al pendiente de su familia. Lo vi muchas veces jugar con sus nietos. Las comidas con su familia los días jueves y el viaje familiar anual eran su

II6. En la inauguración y mesas de homenaje, en el Salón "El Generalito" del Antiguo Colegio de San Ildefonso y ante el rector Enrique Graue, participaron María Teresa Uriarte, coordinadora de Difusión Cultural de la unAM; María Cristina García Cepeda, directora general del InBA; Alberto Vital Díaz, coordinador de Humanidades, unAm; Renato González Mello, director del IIE, de la unam; Gloria Villegas, directora de la Facultad de Filosofía y Letras de la unam. Por su parte, la investigadora emérita, Elisa Vargaslugo, recordó su labor como director del Instituto. En el Museo Nacional de Arte se realizaron las mesas de Historia del Arte I, en las que participaron Martha Fernández, Aurelio de los Reyes García, Gustavo Curiel Leyva, Óscar Flores y Marisol Argüelles. En la segunda mesa, Renato González Mello, Esteban García, Alberto Dallal, Rogelio Ruiz Gomar y Rita Eder. En la mesa de historia participaron Alfredo López Austin, Josefina Vázquez, Álvaro Matute, Andrés Lira, Gisela von Wobeser y Renato González Mello. En el Museo de Arte Moderno se realizaron las mesas: Manrique y los museos; Mesas de arte contemporáneo I y II, y Mesa de proyectos alternos, en las cuales participaron historiadores, académicos y artistas: Magdalena Zavala, Sylvia Navarrete, Miriam Kaiser, Salvador Aceves García, Eloy Tarcisio, Xavier Cortés, Graciela de la Torre, Rita Eder, Elia Espinoza, Teresa del Conde, Manuel Felguérez, Francisco Castro Leñero, Gabriel Macotela, Raúl Herrera y Sebastián Romo, entre otros. 
asunto capital. Lo vi ayudar a su hermano Ignacio y cuando éste enfermó no lo soltó. Disfrutaba ir al mercado de San Juan a comprar queso y pescado, ir a los toros los domingos. Le gustaba fumar sus cigarrillos Delicados y escribir desde su sillón verde. ${ }^{117}$ Caminé con él muchas veces por su jardín, disfrutaba sus árboles frutales, su cafecito chiquito y la fruta en la cena. Vivía acompañado de su perro Aztlán, su perico Baco y mi querida Angelita — su cocinera. ${ }^{\mathrm{II} 8}$ Le gustaba platicar, contar anécdotas y repetirlas una y otra vez, era como si él quisiera llenar mi memoria de su paso por el mundo.

"La verdadera amistad no cancela la posibilidad de disentir. Uno acepta a la persona tal cual es y se sabe aceptada de la misma manera aunque no siempre se esté de acuerdo en ciertas opiniones e ideas". ${ }^{119}$

Un par de días antes de morir recibí un mensaje suyo y ésa fue nuestra despedida.

\section{Obra póstuma}

El maestro trabajó hasta el último día de su vida en su libro La ciudad de México a través de los siglos. Él inició ese proyecto en 1974. El día de la Candelaria de 2009 le pedí que lo retomáramos. Coordiné con él dicha publicación a lo largo de siete años; reemprendimos el trabajo con un grupo numeroso de investigadores elaborando un manuscrito de más de i 000 cuartillas.

El libro recibió la dictaminación favorable en diciembre de 2016 por el Instituto de Investigaciones Estéticas, UNAM, y esperamos su publicación como obra póstuma de Jorge Alberto Manrique.

\section{Colofón}

"Las cosas salidas de nuestra cabeza no las hicimos nosotros, sino otros, aquellos que fuimos: pero no dejan de ser nuestras y no dejamos de reconocernos en

II7. En aquel rinconcito de su casa tenía un cuadro negro de una monja: Sor María de la muerte, obra de Edmundo O'Gorman.

II8. Hay un "proyecto" de una escuela primaria en la sierra de Oaxaca que llevará su nombre. El maestro donó una cantidad de dinero para el traslado del mobiliario que se había conseguido de un convento de monjas. Él estaba muy contento por eso.

II9. Manrique y Del Conde, Cartas absurdas, 8 . 
DOI: http://dx.doi.org/10.22201/iie.18703062e.2017.1.2599

318

MIGUEL ÁNGEL ROSAS

ellas. Hay quienes cambian de sopetón: se convierten a una idea (¿o a una religión?) y abjuran de lo anterior. Muy su derecho. No es mi caso. Mis maneras de pensar al enfrentarme al hecho artístico nunca han sido zarandeadas de forma súbita, pero no menos habrán ido modificándose en el curso de los años, y quizá yo sea quien menos me dé cuenta, así como cada uno es el que menos advierte su envejecimiento." 220

Descanse en paz, querido, muy querido maestro.\$

I20. Jorge Alberto Manrique, “Colofón”, en Manierismo en México (México: Textos Dispersos, 1993), 57 . 